\title{
Seismic loss estimation for efficient decision making
}

\author{
B.A. Bradley, R.P. Dhakal, M. Cubrinovski, G.A. MacRae \\ Department of Civil and Natural Resources Engineering, University of \\ Canterbury, Christchurch, New Zealand.
}

D.S. Lee

Department of Mathematics and Statistics, University of Canterbury, Christchurch, New Zealand.

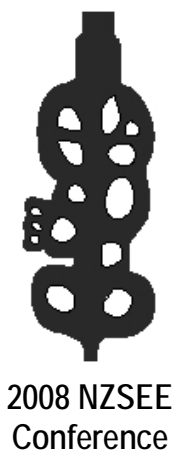

\begin{abstract}
In order to incorporate seismic risk of facilities into a decision making framework, procedures are needed to quantify such risk for stakeholders. Seismic loss estimation methods combine seismic hazard, structural response, damage fragility, and damage consequences to allow quantification of seismic risk. This paper presents a loss estimation methodology which allows various means of quantifying seismic risk of a specific facility. The methodology is component-based and can therefore distinguish between different structural configurations or different facility contents and is consistent with state-of-the-art loss assessment procedures. Loss is measured in the forms of direct structural and non-structural repair costs, and although not considered in the example, business disruption and occupant casualties can also be considered. This framework has been packaged in a computer code available for future dissemination in the public domain so that users need only to have a basic understanding of the methodology and the input data that is required. Discussion is given to the flexibility of the framework in terms of the rigour which can be employed at each of the main steps in the procedure. Via a case study of a high-rise office building, the use of the methodology in decision-making is illustrated. Methodological requirements and further research directions are discussed.
\end{abstract}

\section{INTRODUCTION}

Current seismic design codes provide guidelines for the design and detailing of structures with the primary goal of preventing global collapse during strong ground motion shaking. Observations from worldwide earthquakes in the past two decades have illustrated that with few exceptions, structures designed to these state-of-practice guidelines are sufficient for providing life safety with a high degree of confidence. However, these events illustrated the severe economic consequences resulting from earthquakes in highly developed regions of society. These economic consequences can be primarily attributed to: (i) direct economic losses associated with repairing damage within a structure; (ii) direct losses associated with injuries and casualties; and (iii) indirect losses associated with the loss of income due to business disruption. These three forms of losses (damage, death and downtime) are known as the '3D's'. Some examples from the United States include the 1994 Northridge (\$17-26 billion), and 1989 Loma Prieta ( $\$ 11$ billion) earthquakes (III, 2006). In response to these observed losses it has become apparent that seismic design of structures should consider all of these potential consequences and their likelihood of occurrence.

Quantification of seismic risk is a difficult task which is subject to inherent variability. Although it can be roughly forecasted, it is not known when and where future significant fault ruptures will occur. Even when an earthquake occurs at a particular location, due to the complex rupture mechanism, process of seismic wave propagation and site effects, the intensity, frequency content and duration of ground motions at a particular site are also uncertain. These uncertainties in the strong ground motions affecting a given site cause corresponding uncertainty in the level of structural response, and associated damage in the structure. Finally, the cost to repair a damaged structure is also uncertain and depends on available resources and demand. In order to rigorously assess the seismic risk of a structure all of the above uncertainties should be accounted for. Thus it becomes necessary that the 
problem of seismic risk is cast into a probabilistic framework which can propagate such uncertainties in each of the input variables and give a probabilistic output useful for decision making processes.

These aforementioned uncertainties result from either inherent randomness in a process, or uncertainty due to the limited knowledge and application of engineering models. These two different types of uncertainty are referred to as aleatory randomness and epistemic uncertainty, respectively. An example of aleatory randomness would be the variation in the level of ground motion observed at a site due to different ground motions resulting from the same rupture magnitude and source-to-site distance, while epistemic uncertainty would result from the ground motion prediction equation used to estimate the level of ground motion at the site. As aleatory randomness is deemed as an inherent property of complex phenomena, it cannot be reduced; epistemic uncertainty being knowledge-based can be reduced if better knowledge of the phenomena is acquired. As these two different uncertainties are related to different aspects of the considered problem they deserve separate treatment within a decision making process.

This paper presents a discussion of the use of seismic loss estimation for decision making at various stages of design and/or seismic assessment of structures. An outline of the state-of-the-art seismic loss estimation is given with reference to a specific case study of a 10-storey New Zealand commercial office building. Using the case study structure a full loss assessment is performed and discussion is given to each of the possible outputs for decision making. Some simplistic assumptions are made in the loss assessment in order to accomplish the goal of this manuscript which is to present the interpretation of loss assessment results for use in decision making. For simplicity, this paper is primarily concerned with aleatory randomness only. These assumptions are revisited at the end of the manuscript where further discussion is given to the effects of relaxing such assumptions.

\section{CASE STUDY STRUCTURE}

The case study structure used herein to illustrate the use of seismic loss estimation tools in decision making process is based on the Red Book building (Bull and Brunsden, 1998) which acts as a design example of the New Zealand Concrete Code (NZS3101:1995). Figure 1 illustrates plan and elevation views of the building layout. The primary lateral load carrying system consists of four one-way perimeter moment resisting frames which are 3 bays long. Vertical loads are transferred primarily through interior columns with gravity beams supporting one-way floor units. Although originally designed for a site in Christchurch, in this study it was assumed that the structure is located at a site in Wellington. The soil is assumed to be class A (NZS1170.1, 2004) and stiff enough so that local site effects are not significant in modifying the bedrock ground motion.

A 2D model of perimeter frame was developed using the time-history analysis program Ruaumoko2D (Carr, 2004). Due to the symmetry of the structure, it was assumed that the 3D response could be reasonably approximated by separate $2 \mathrm{D}$ analyses in each of the two primary directions. A fixed-base model was used in the analysis and as a result soil-structure-foundation interaction was neglected. The structure was modelled using a lumped mass model and non-linear (beam) elements based on the modified Takeda hysteresis, with the appropriate section properties determined using fibre-based biaxial section modelling. The structural model had a fundamental period of 1.5 seconds. Further details on the structural response and the effects of the assumptions on the loss estimation outcome are discussed later in the manuscript. 

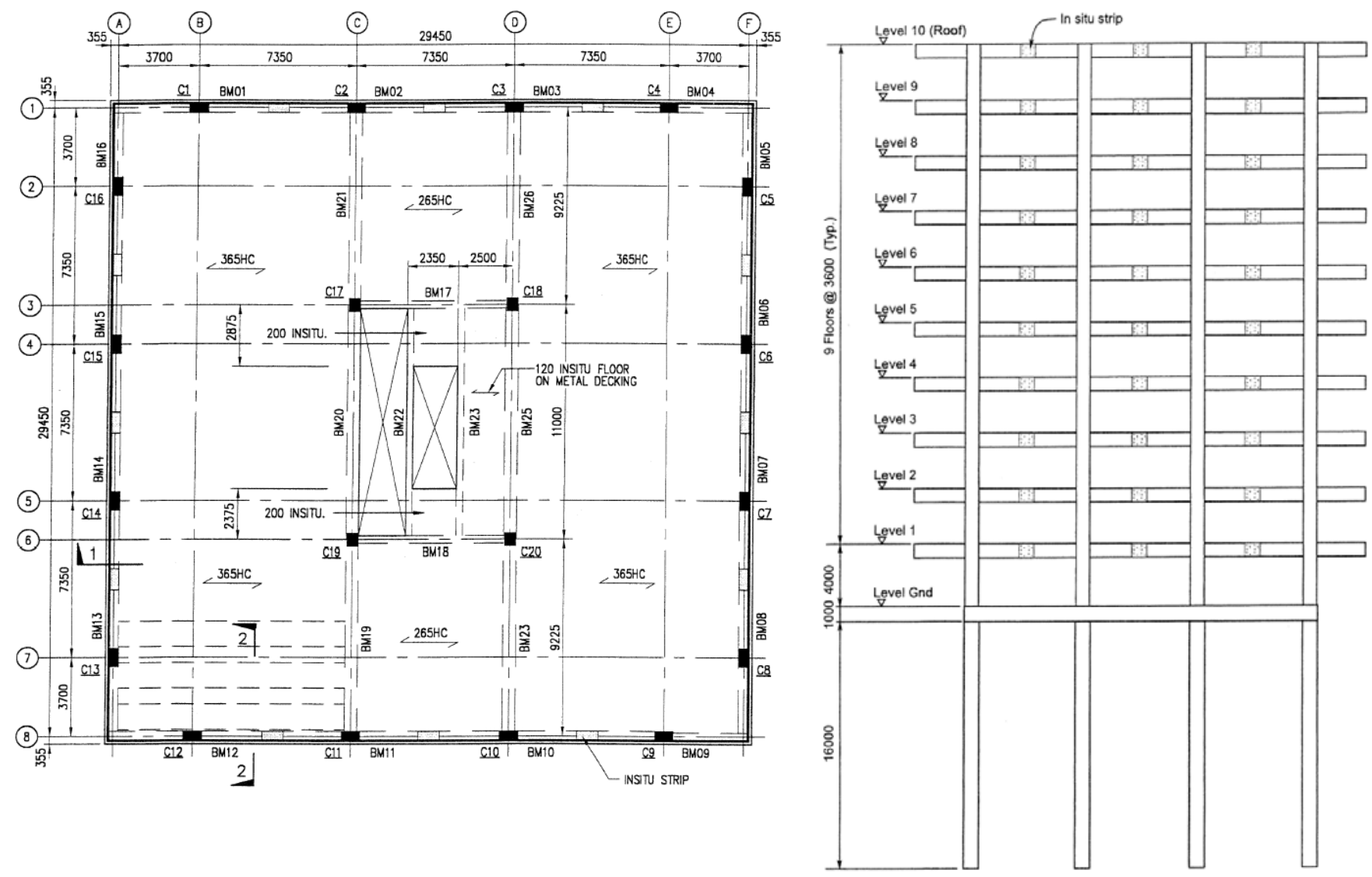

Figure 1: (a) Plan, and (b) elevation of the Red Book building (Bull and Brunsden, 1998).

\section{SEISMIC HAZARD}

The seismic hazard at the site of the structure can be quantified by performing a probabilistic seismic hazard analysis (PSHA). PSHA combines the magnitude recurrence relationships of various earthquake sources, and a ground motion prediction relationship. The ground motion prediction relationship describes the level of ground motion shaking at a site as a function of the magnitude of the earthquake and faulting type; source-to-site distance and path effects; local site effects; and soil amplification. The results of a PSHA is a ground motion hazard curve which gives the annual frequency of exceeding specific values of ground motion intensity. In this study, the ground motion hazard for Wellington based on Stirling et al, (2002) was employed. As the fundamental period of the structure is 1.5 seconds, the $5 \%$ damped spectral acceleration at this period, $S_{a}(\mathrm{~T}=1.5 \mathrm{~s}, 5 \%$ ) (or simply $S_{a}$ for brevity) is chosen as the ground motion intensity measure (IM). This selection of ground motion IM is based on the observation from past researchers (e.g. Shome and Cornell, 1999) that the spectral acceleration at the fundamental period of the structure is an 'efficient' IM at predicting the drift demands in the structure. An efficient IM is desired as a reduction in the uncertainty in the structural response will result in a reduction in the uncertainty in the magnitude of economic losses. Figure 2 illustrates the seismic hazard curve obtained via PSHA which (in this case) describes the mean annual frequencies of exceeding various levels of $S_{a}$. The two reference lines are indicated in the plot represent $10 \%$ and $2 \%$ probability of exceedance in 50 years (return periods of 475 and 2475 years, respectively) which are typical frequencies used when determining forces/displacements for the design and assessment of structures. 


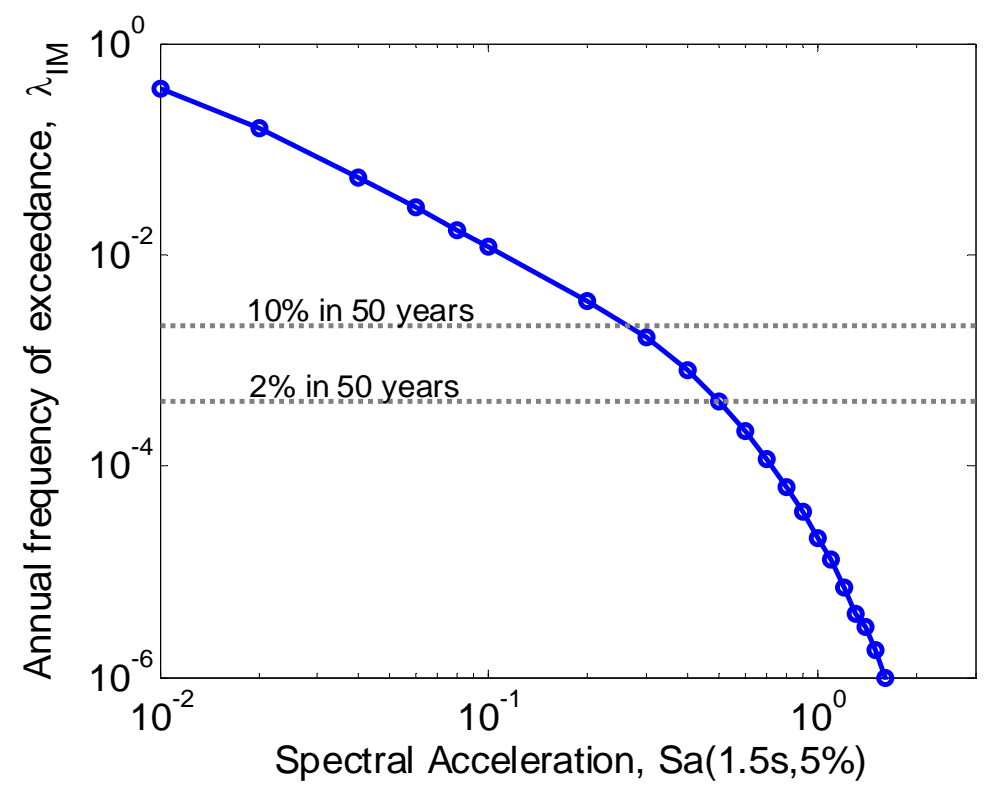

Figure 2: Ground motion hazard curve for Wellington, New Zealand, (Stirling et al, 2002).

\section{SEISMIC RESPONSE ANALYSIS}

Seismic response analysis of the structure was performed using non-linear time history analysis with a suite of ground motions scaled over a wide range of ground motion intensities to account for the variability in structural response due to differences in ground motions of the same intensity (termed record-to-record randomness). A suite of 40 ground motion records complied by Medina and Krawinkler (2003) were used for conducting the non-linear time history analyses. The suite contains ground motions recorded on stiff soil with magnitude and distance ranges of 6.5-6.9 and 13.3-39.3 km, respectively. The suite is termed 'ordinary' by Medina and Krawinkler, as none of the records show effects of near-fault motions (i.e. directivity or 'fling' effects), and all ground motions were recorded on stiff soils. As the Wellington seismic hazard will likely have some dominance due to near-fault records, in a more rigorous assessment the suite of ground motions should incorporate near-fault ground motions (which more accurately match the likely spectral shapes of future ground motions), however this is beyond the scope of this paper.

In the example presented herein, the seismic response is evaluated rigorously using time history analyses with multiple ground motions. In preliminary investigations however, it may not be feasible to conduct such rigorous analyses. In such cases there are various simplified methods which may be used to approximate the 'true' seismic response obtained by direct non-linear time-history analysis. Such methods can be of a pseudo-static nature or modal pushover methods coupled with singledegree-of-freedom (SDOF) time history analyses (e.g. Moghadam and Tso, 2000; Fajfar, 2002; Penelis and Kappos, 2002; and Chopra and Goel, 2004).

The suite of ground motions were scaled to $S_{a}$ values ranging from $0.1-1.5 \mathrm{~g}$ in increments of $0.1 \mathrm{~g}$. Thus in total, 600 non-linear time history analyses were completed using 40 different ground motion records at 15 different intensities. This process of incrementally carrying out time history analysis using ground motion records to various levels of intensity is termed Incremental Dynamic Analysis (IDA) (Vamvatsikos and Cornell, 2002). IDA allows quantification of the seismic demand and capacity of the structure from initial elastic response through to global collapse. Herein the interstorey drift (or drift for brevity) between two floors is denoted as the interstorey drift occurring in the lower of the two floors (i.e. the second floor interstorey drift is the interstorey drift between the second and third floors). This terminology is adopted to allow clarity in later discussions considering loss due to both drift and acceleration demands. Figure 3 illustrates two IDA results representing the maximum interstorey drifts (the Engineering Demand Parameter, EDP) on the second and eighth floors of the 
analysed structure as a function of the ground motion IM. Each of the points in the figures is the result of a single time history analysis when global structural collapse did not occur, while the two lines indicate the mean response for a given level of intensity with and without consideration of global collapse, respectively (discussion on computing these two quantities is given further in the manuscript). The fewer number of analysis points in the figure at higher levels of ground motion intensity is due to the fact that a larger proportion of ground motions cause collapse (and are therefore not displayed).
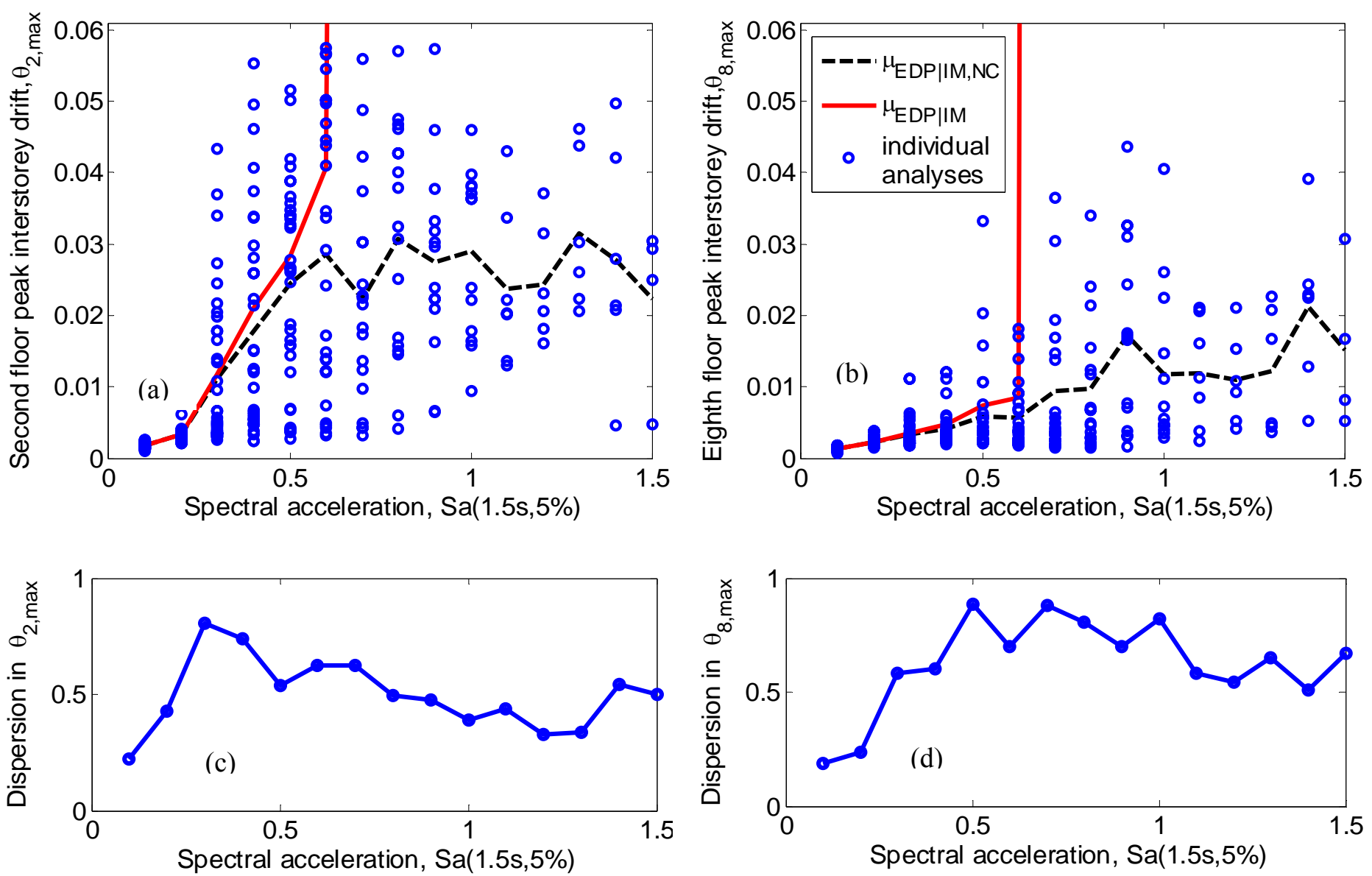

Figure 3: Examples of IDA plots of maximum interstorey drift for the (a) second-third storey; (b) seventh-eighth story; (c) dispersion in second-third storey drift response; and (d) dispersion in seventh-eighth storey drift response.

As is evident in Figures $3 a$ and $3 b$ there exists a significant amount of variation in the seismic response of the structure for various levels of ground motion, with the variation increasing as the level of intensity increases (primarily due to significant non-linear response of the structure). This uncertainty can be quantified by computing the dispersion (standard deviation of the logarithm of the analysis data where collapse does not occur) of the responses as a function of intensity which is shown in Figures $3 \mathrm{c}$ and $3 \mathrm{~d}$. Dispersion is used as the measure of variation as it has been shown by various researchers that this variation can be well approximated by the lognormal distribution (e.g. Aslani and Miranda, 2005; Mander et al. 2006). The dispersion, $\beta$, is related to the non-log moments of the variable by (Ang and Tang, 1975):

$$
\beta^{2}=\sigma_{\ln X}^{2}=\ln \left(\left[\frac{\sigma_{X}}{\mu_{X}}\right]^{2}+1\right)
$$


where $\mu_{X}$ and $\sigma_{X}$ are the mean and standard deviation of the variable $X$. For reference, it can be shown that a first order (Taylor series) approximation of Equation 1 is $\beta \approx \delta$, where $\delta=\sigma / \mu$ is the coefficient of variation (cov).

With the mean and dispersion of the seismic response (given no collapse) known, for a given level of intensity, the probability of exceeding some level of demand can be obtained from:

$$
G(E D P \mid I M)=G(E D P \mid I M, N C)[1-P(C \mid I M)]+P(C \mid I M)
$$

where $G(x \mid y)$ is given as shorthand notation for the complementary cumulative distribution function (CCDF) of $x$ given $y, G(X>x \mid Y=y$ ) (Ang and Tang, 1975); $G(E D P \mid I M, N C)$ gives the probability of exceeding EDP given IM and no collapse, and $P(C \mid I M)$ is the probability of collapse given IM (defined in the subsequent section). The mean demand considering both collapse and noncollapse cases (shown in Figures $3 \mathrm{a}$ and $3 \mathrm{~b}$ ) can be computed indirectly from Equation 2. Specific details on this computation can be found in Jalayer (2003).

The variation in the seismic demand through different elevations is illustrated in Figure 4 which shows the (mean) peak interstorey drifts and (mean) peak floor accelerations as a function of the elevation in the building. Note that the values in the figure represent the mean of many ground motion records and each of the different values will not likely occur at the same time (i.e. these are not profiles at a specific step in time). As is typical for a multi-storey frame structure the drift demands are observed to be the most severe in the lower half of the structure, while the (total as opposed to relative) acceleration demands are approximately constant over the height of the structure for low levels of shaking, but become larger in the lower stories for higher levels of ground motion when significant damage in the lower floors occurs (i.e. the damaged floors begin to isolate the upper region of the structure). It will be shown later in the manuscript that this localization of drift and acceleration demands at high levels of ground motion (without the occurrence of global collapse) in the lower stories of the structure prevents significant damage to components in the upper stories.
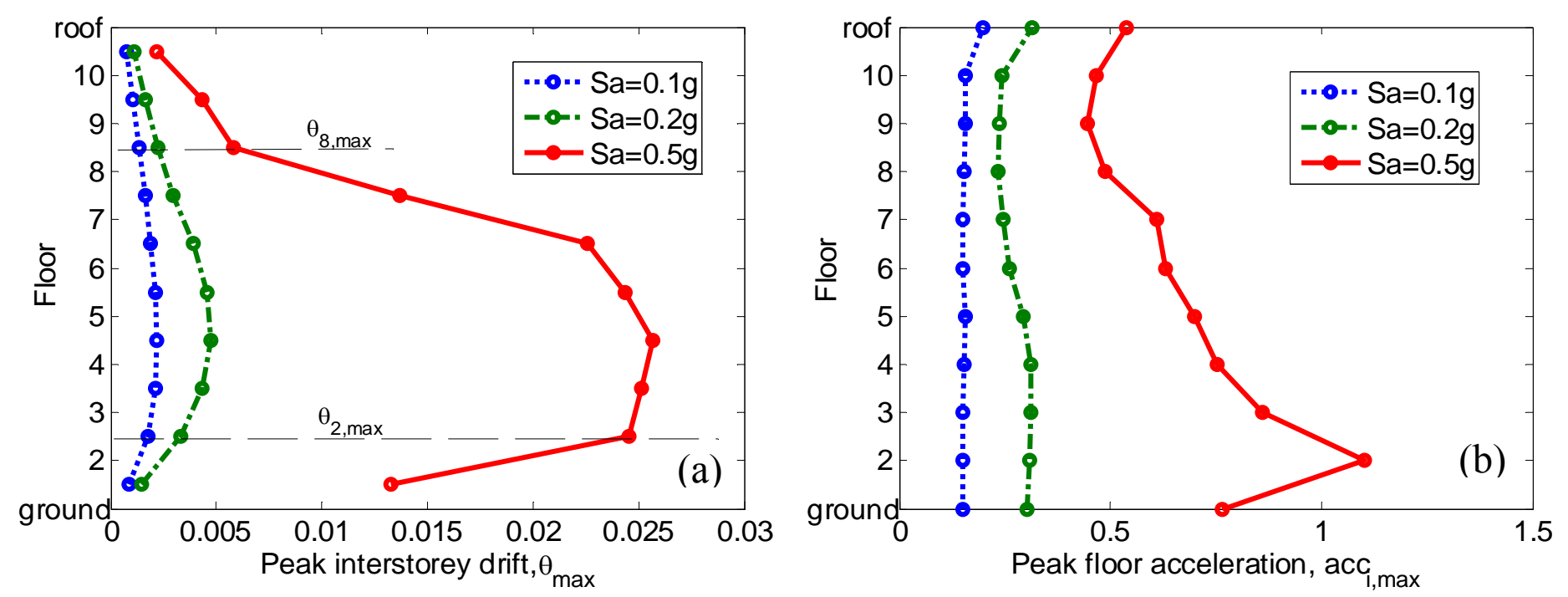

Figure 4: Variation in (a) mean drift and (b) mean acceleration demands over the height of the structure.

\section{OCCURRENCE OF GLOBAL COLLAPSE}

In loss assessments as well as for decision making purposes it is beneficial to consider separately global collapse cases and non-collapse cases (Shome and Cornell, 2000). From a loss assessment perspective, this is done as the loss due to global collapse can not simply be obtained by summing the losses for each component within the structure (which is the case when global collapse does not 
occur). This is because post-earthquake reconstruction for a structure which has sustained global collapse generally involves demolition of the structure and replacement by a new one, and thus some components which may not be damaged are nevertheless replaced. From a seismic response viewpoint, if global collapse is not considered separately then the assumption of the EDP|IM relationship having a lognormal distribution is likely to be violated (Aslani, 2005). Finally, by separately considering global collapse it is possible to determine the likelihood of global collapse for a given earthquake scenario or as a probability over the lifetime of the structure, which is an important measure in assessing seismic performance (Zarein and Krawinkler, 2007).

Traditionally, the occurrence of structural collapse has been associated with some prescribed level of seismic demand, such as interstorey drift or component plastic deformation. This however does not account for the redundancy of structural systems which allows for redistribution of damage and global stability despite local failures (Zarein and Krawinkler, 2007). Here collapse is defined as the state in which sidesway instability occurs in one or more storeys. Collapse due to loss of vertical carrying capacity (LVCC) (due to axial and critical shear failures) is not considered due to a lack of structural analysis tools which can reliably capture these phenomena, although work is progressing rapidly in this area (e.g. Elwood and Moehle, 2008). From IDA results a collapse fragility curve can be constructed by first determining the probability of collapse for various levels of ground motion intensity (based on the proportion of records which cause structural collapse), and then typically fitting these raw data points with a lognormal distribution. Figure 5 illustrates the collapse fragility curve for the case study structure. Note that analyses were only conducted up to $1.5 \mathrm{~g} S_{a}$, and thus extrapolation is needed to describe the probability of collapse at higher intensity levels. As will be shown later, the infrequent occurrence of such events (larger than $1.5 \mathrm{~g} S_{a}$ ) means that these levels of intensity do not significantly affect the results in the loss analyses. It is also noted that the hysteresis used for the structural elements in the Ruaumoko2D structural model considers strength and stiffness degradation but not cyclic degradation which can be significant for responses to ground motions of significant duration. It is also possible to account for collapse due to LVCC based on a weakest-link concept using the collapse fragilities of all structural components within the structure (Aslani, 2005), but is not done so in this example. The two aforementioned points result in a collapse fragility curve shown in Figure 5 to be unconservatively biased, however it is used here for the purposes of illustration.

In conceptual design phases it is not feasible to obtain the collapse fragility curves from time-history analysis. In such cases, it is recommended to use the results of Medina and Krawinkler, (2003) and Ibarra and Krawinkler, (2005) who have conducted extensive analysis on the collapse capacity of frame and wall systems of various geometry and hysteretic behaviour, and provide simple estimates of the median level of intensity causing global collapse.

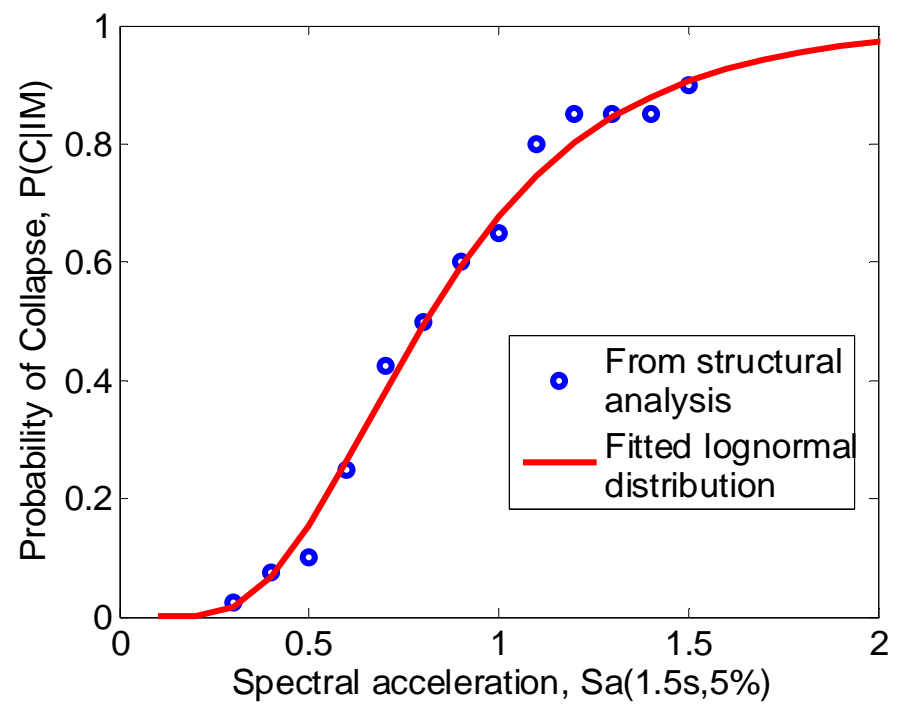

Figure 5: Collapse fragility curve for case study structure 


\section{STRUCTURAL RESPONSE AND COLLAPSE HAZARDS}

The results of the seismic response analysis can be combined with the ground motion hazard to provide the rates of exceedance for various levels of seismic demand on the structure. For example, by combing the collapse fragility curve and the ground motion hazard, it is possible to compute the annual rate of global collapse by:

$$
\lambda_{C}=\int P(C \mid I M)\left|\frac{d \lambda_{I M}}{d I M}\right| d I M
$$

where $\lambda_{C}$ is the annual rate of structural collapse; $P(C \mid I M)$ is the probability of collapse for a given level of IM obtained from the collapse fragility curve (Fig. 5) and $\lambda_{I M}$ is the ground motion hazard curve (Fig. 2). Equation 3 is simply an application of the total probability theorem and indicates that the annual rate of structural collapse can be obtained by multiplying the probability of collapse for a given IM with the likelihood of that level of IM occurring, and then summing over all the possible values of IM. As historical and recent earthquake reconnaissance indicate that structural collapse is the primary source of casualties and loss of life caused by earthquakes, then the annual rate of structural collapse is a key performance criterion for use in seismic assessment of structures. Also, since the primary purpose of current standards is to implicitly design structures that will provide life safety by maintaining structural integrity, then Equation 3 provides an explicit method for assessment of this implicit objective of code-designed structures. For the case study structure considered in this paper it was found that the annual rate of collapse is $2.15 \times 10^{-4}$, which (based on the Poisson assumption) corresponds to a $1.1 \%$ probability of global collapse of the structure over a service life of 50 years. As previously mentioned, the collapse fragility curve was unconservatively biased since LVCC and cyclic deterioration were ignored, and accounting for these two effects is likely to slightly increase the annual rate of collapse.

Similar to the annual rate of collapse, the seismic response for a particular EDP can be combined with the ground motion hazard curve to obtain the annual rate of exceeding various levels of EDP (herein referred to as an EDP hazard curve) by:

$$
\lambda_{E D P}=\int G(E D P \mid I M)\left|\frac{d \lambda_{I M}}{d I M}\right| d I M
$$

where $\lambda_{E D P}$ is the annual rate of exceeding the prescribed level of EDP.

Figures $6 \mathrm{a}$ and $6 \mathrm{~b}$ illustrate the EDP hazard curves for interstorey drifts and accelerations, respectively for the investigated structure. Several things should be noted from Figure 6 in relation to the results from the structural analysis (Fig. 3-5) and the ground motion hazard (Fig. 2). Firstly, all of the hazard curves have an asymptote at $\lambda=2.15 \times 10^{-4}$ which is the annual rate of global collapse. Secondly, for a given level of exceedance rate the values for each of the lines (representing different floors) can be used to create figures similar to that of Figure 4, for different levels of annual rate of exceedance. Finally, the location of the lines relative to each other therefore describes how the distribution of seismic demand changes over the height of the structure as a function of ground motion intensity. For example, since all of the drift EDP hazard curves remain relatively parallel to each other it indicates that the hierarchy of interstorey drifts over the height of the structure remains relatively unchanged as the level of IM increases. However, for the acceleration EDP hazard curves it is immediately apparent that the curve for the roof acceleration crosses over the ground, $2^{\text {nd }}$ and $6^{\text {th }}$ floor acceleration curves as the rate of exceedance decreases. This indicates that the roof acceleration which is larger than the maximum acceleration of other floors for small levels of ground shaking gradually becomes less than the maximum acceleration of several floors as the ground motion level increases (this same observation can be seen in Figure $4 \mathrm{~b}$ as $S_{a}$ increases). 

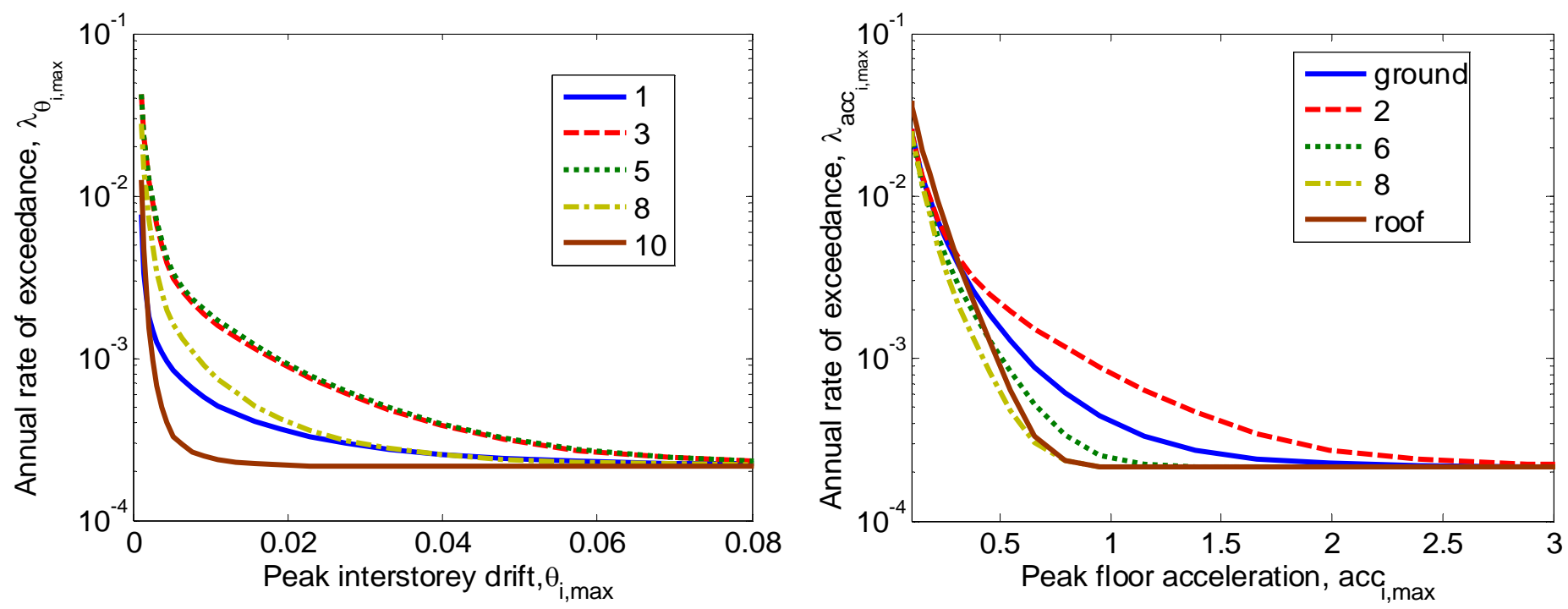

Figure 6: EDP hazard curves of (a) peak interstorey drift; and (b) peak floor accelerations for the case study structure.

\section{COMPONENT INVENTORY OF STRUCTURE}

In order to carry out loss estimation for a specific structure, an inventory of components and their location within the structure is required. The level of detail regarding quantity estimates for each of the components within the structure will depend on the state which the structure is in when the assessment is carried out. In a retrofit assessment where all of the component quantities are known exactly is significantly different compared to the preliminary stage of assessing various structural design configurations. Table 1 gives a list of approximate densities of various non-structural components and contents in office buildings based on Aslani, (2005); Mitrani-Reiser (2007); and Buchan (2007) which is likely to be useful in the latter design scenario.

Table 1: Typical densities of non-structural components and contents in office buildings

\begin{tabular}{|c|c|c|}
\hline Component & Description & Density \\
\hline $\begin{array}{c}\text { Interior partitions, finish, and } \\
\text { paint }\end{array}$ & $\begin{array}{c}16 \mathrm{~mm} \text { 1-side partition on metal } \\
\text { stud (same for finish). }\end{array}$ & $\begin{array}{c}0.8 \mathrm{~m}^{2} \text { Partition } / \mathrm{m}^{2} \text { floor area } \\
\text { (FA) (Mitrani-Reiser, 2007) }\end{array}$ \\
\hline $\begin{array}{c}\text { Exterior glazing } \\
\begin{array}{c}1.5 \mathrm{~m} \times 1.8 \mathrm{~m} \text { standard glass } \\
\text { panes }\end{array}\end{array}$ & $\begin{array}{c}1.3 \text { panes / m floor perimeter } \\
\text { (Mitrani-Reiser, 2007) }\end{array}$ \\
\hline Acoustical ceiling & $\begin{array}{c}0.6 \mathrm{~m} \times 1.2 \mathrm{~m} \text { tiles with } \\
\text { Aluminium frames } \\
\text { (Mitrani-Reiser, 2007) }\end{array}$ \\
\hline Automatic sprinklers & $\begin{array}{c}3.7 \mathrm{~m} \text { sections of sprinkler } \\
\text { piping }\end{array}$ & $\begin{array}{c}0.08 \text { sections / } \mathrm{m}^{2} \text { FA (Mitrani- } \\
\text { Reiser, 2007) }\end{array}$ \\
\hline Servers and network equip & Typical & $\$ 235 / \mathrm{m}^{2}$ FA (Buchan, 2007) \\
\hline Computers and printers & Typical & $\$ 102 / \mathrm{m}^{2} \mathrm{FA}$ (Buchan, 2007) \\
\hline Bookcases and file cabinets & Typical & $\$ 9 / \mathrm{m}^{2}$ FA (Buchan, 2007) \\
\hline Roof mounted equipment & Coolers, airconditioning etc. & $\$ 64 / \mathrm{m}^{2}$ FA (Buchan, 2007) \\
\hline Workstation desks & Typical & $\$ 24 / \mathrm{m}^{2}$ FA (Buchan, 2007) \\
\hline Generic acceleration sensitive & $\begin{array}{c}\text { fire protection systems, HVAC, } \\
\text { Heating, cooling, pumps. }\end{array}$ & $\$ 110 / \mathrm{m}^{2}$ FA (Aslani, 2005) \\
\hline Generic drift sensitive & $\begin{array}{c}\text { vertical piping, bath tubs, } \\
\text { F.H.C, Ducts }\end{array}$ & $\$ 110 / \mathrm{m}^{2}$ FA (Aslani, 2005) \\
\hline
\end{tabular}


When conducting a loss assessment of a structure, it is important to consider all of the components which have the potential to significantly contribute to the loss due to earthquakes causing a wide range of shaking intensities. Taghavi and Miranda, (2003) researched typical cost distributions for office, hotel and hospital buildings. In all three building types they found that each of the different component types (structural, non-structural and contents) are important. For the office building considered in this study the components listed in the first column of Table 2 have been considered.

Table 1 was used to determine the quantities for the non-structural and contents components, while quantities for the structural components were obtained directly from building drawings (Fig. 1). It was assumed that all of the contents and non-structural components had equal densities over the height of the building with the exception of the roof mounted equipment (located on the roof only), server and network equipment (located on the $3^{\text {rd }}, 6^{\text {th }}$, and $10^{\text {th }}$ floors), and elevators (ground floor). All information regarding the specifications of each of the various components can be found in Bradley (2008).

Each different component has its own fragility and loss functions which are defined based on the various damage states requiring repair that the component could be in following the earthquake. In this example loss was considered as that due to direct repair costs of replacing the structure to its original state and losses due to deaths and downtime were not considered. Fragility and loss function for all of the components in Table 2 can be found in Bradley (2008), and therefore only a single example is outlined here to illustrate the methodology.

Table 2: Quantities used in the case study example

\begin{tabular}{|c|c|c|}
\hline Component & Description & Quantity \\
\hline Ductile beam-column joints & $\begin{array}{c}\text { Post } 1960 \text { s ductile beam column } \\
\text { joints ( } 2 \text { beams) }\end{array}$ & 24 / floor \\
\hline Columns & $\begin{array}{l}\text { Gravity columns (and seismic } \\
\text { columns on first floor) }\end{array}$ & $\begin{array}{l}20 \text { on } 1^{\text {st }} \text { floor, } 4 \text { on all other } \\
\text { floors }\end{array}$ \\
\hline Slab-beam-column connections & $\begin{array}{c}\text { Connection of slab to seismic } \\
\text { frame }\end{array}$ & 24 / floor \\
\hline Partition & Drywall partitions and finish & $721 \mathrm{~m}^{2} /$ floor \\
\hline Exterior glazing & $\begin{array}{c}1.5 \mathrm{~m} \times 1.8 \mathrm{~m} \text { standard glass } \\
\text { panes }\end{array}$ & 99 panes / floor \\
\hline Acoustical ceiling & $\begin{array}{l}0.6 \mathrm{~m} \times 1.2 \mathrm{~m} \text { tiles with } \\
\text { Aluminium frames }\end{array}$ & 693 tiles / floor \\
\hline Automatic sprinklers & $\begin{array}{l}3.7 \mathrm{~m} \text { sections of sprinkler } \\
\text { piping }\end{array}$ & 23 sections / floor \\
\hline Servers and network equip & Typical & $\$ 260,000$ on floors 3,6 , and 10 \\
\hline Computers and printers & Typical & $\$ 93000$ / floor \\
\hline Bookcases and file cabinets & Typical & $\$ 16200$ / floor \\
\hline Roof mounted equipment & Coolers, airconditioning etc. & $\$ 600,000$ on roof \\
\hline Workstation desks & Typical & $\$ 21600$ / floor \\
\hline Generic acceleration sensitive & $\begin{array}{c}\text { fire protection systems, HVAC, } \\
\text { Heating, cooling, pumps, } \\
\text { plumbing, toilets }\end{array}$ & $\$ 100,000$ / floor \\
\hline Generic drift sensitive & $\begin{array}{l}\text { vertical piping, bath tubs, } \\
\text { F.H.C, Ducts }\end{array}$ & $\$ 100,000$ / floor \\
\hline
\end{tabular}




\section{LOSS DEMAND RELATIONSHIP}

Figures $7 \mathrm{a}$ and $7 \mathrm{~b}$ illustrate fragility and loss functions for the four damage states used to define the seismic performance of ductile reinforced concrete beam-column joints. For each of the damage states there is uncertainty (represented here by cumulative lognormal distributions) due to randomness in the strengths of the joints and the cost to repair the various levels of damage. Such fragility functions for structural components are typically obtained from a database of experimental results, although analytical methods and expert opinion can also be used (Porter et al, 2007), while the loss functions are typically obtained by employing a professional cost estimator (e.g. Mitrani-Reiser, 2007).
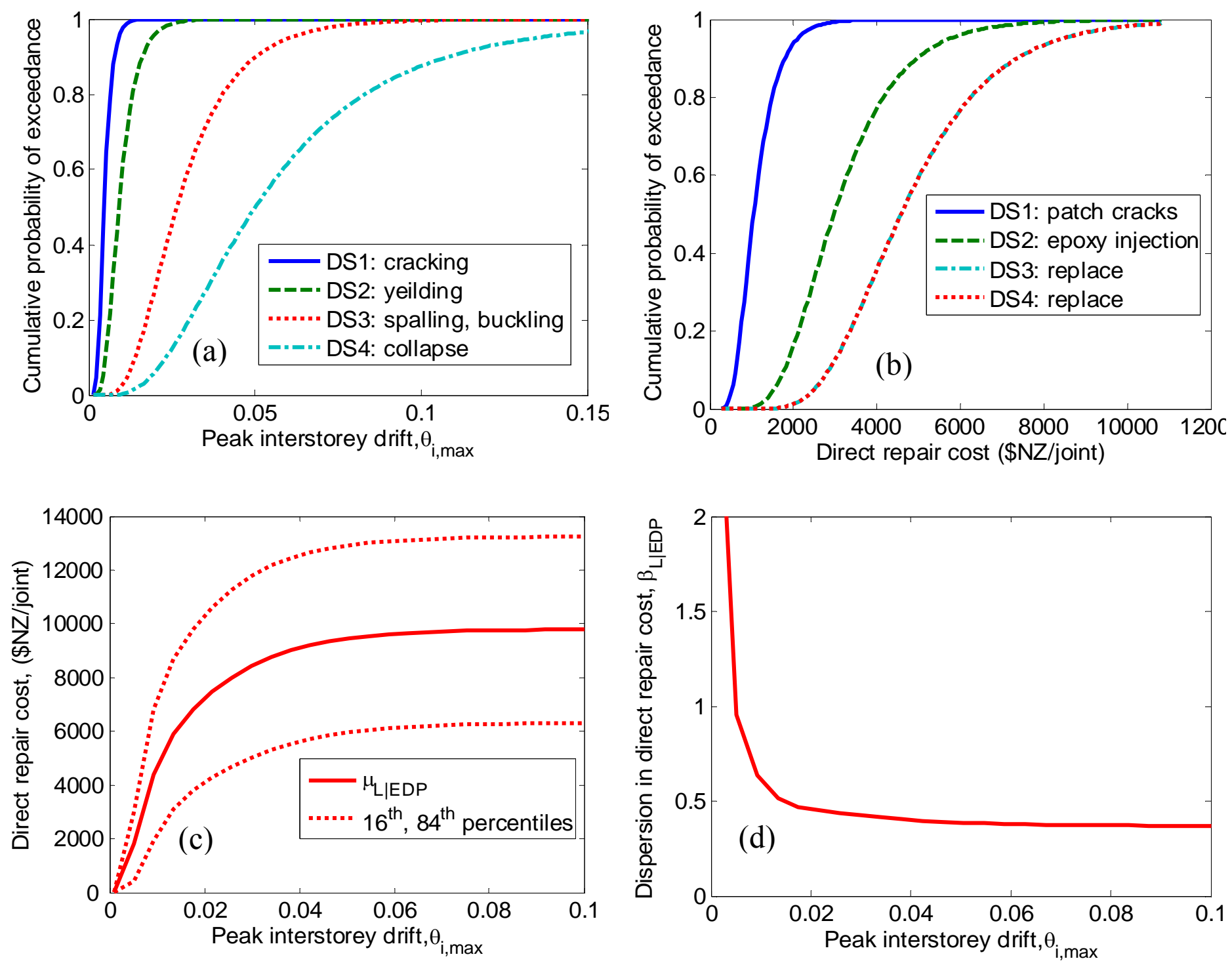

Figure 7: Illustration of (a) fragility functions; (b) loss functions; (c) mean and \pm one standard deviation loss|EDP; and (d) dispersion in loss|EDP for a ductile RC beam-column joint.

The fragility and loss functions can be combined to compute the mean and variance of the loss for a given level of EDP by the following equations:

$$
\mu_{L_{i} \mid E D P}=\sum_{j=1}^{N_{D S}} \mu_{L_{i} \mid D S_{j}} P\left(D S_{j} \mid E D P\right)
$$




$$
\sigma_{L_{i} \mid E D P}^{2}=\sum_{j=1}^{N_{D S}}\left[\mu_{L_{i} \mid D S_{j}}^{2}+\sigma_{L_{i} \mid D S_{j}}^{2}\right] P\left(D S_{j} \mid E D P\right)-\mu_{L_{i} \mid E D P}^{2}
$$

where $\mu_{L_{i} \mid E D P}$ and $\sigma_{L_{i} \mid E D P}^{2}$ are the mean and variance of the loss for a given level of EDP; $\mu_{L_{i} \mid D S_{j}}$ and $\sigma_{L_{i} \mid D S_{j}}^{2}$ are the mean and variance in the loss-damage state (L/DS) relationship (Fig. 7b); $N_{D S}$ is the number of damage states; and $P\left(D S_{j} \mid E D P\right)$ is the probability of being in damage state $D S_{j}$ given demand level EDP which can be computed as the vertical distance between the fragility curves shown in Figure 7a:

$$
P\left(D S_{j} \mid E D P\right)=\left\{\begin{array}{cc}
G\left(D S_{j} \mid E D P\right)-G\left(D S_{j+1} \mid E D P\right) & j \neq N_{D S} \\
G\left(D S_{j} \mid E D P\right) & j=N_{D S}
\end{array}\right.
$$

where $G\left(D S_{j} \mid E D P\right)$ is the probability of exceeding $D S_{j}$ given demand level EDP (i.e. from the fragility curves in Figure 7a). Figure 7c illustrates the mean and mean \pm one standard deviation values for the L|EDP relationship for the RC joint, while Figure 7d illustrates the dispersion in the loss as a function of EDP. The large dispersion for small EDP values apparent in Figure 7d is typical of L|EDP curves for various types of components. This is due to a large standard deviation in the loss and a small mean loss.

\section{LOSS GIVEN INTENSITY RELATIONSHIP}

\subsection{L|IM for an individual component}

The L|EDP relationships previously discussed are useful in observing the seismic performance of various components, however it is more insightful to combine these L/EDP relationships with the seismic response (EDP|IM) relationship in order to determine the loss as a function of ground motion intensity (L/IM relationship), both for individual components, and for the entire structure. The mean and variance in the loss for an individual component as a function of the ground motion IM can be obtained from:

$$
\begin{aligned}
& \mu_{L_{i} \mid I M}=\int \mu_{L_{i} \mid E D P} f_{E D P \mid I M} d E D P \\
& \sigma_{L_{i} \mid I M}^{2}=\int\left[\mu_{L_{i} \mid E D P}^{2}+\sigma_{L i E D P}^{2}\right] f_{E D P \mid I M} d E D P-\mu_{L_{i} \mid I M}^{2}
\end{aligned}
$$

where $\mu_{L_{i} \mid E D P}$ and $\sigma_{L i E D P}^{2}$ are obtained from Equations 5 and 6, respectively; and $f_{E D P \mid I M}$ is the probability density function (pdf) for the EDP|IM relationship, which can be obtained from

$$
f_{E D P \mid M}=-\frac{d G(E D P \mid I M, N C)}{d E D P}
$$

where $G(E D P \mid I M, N C)$ is obtained from seismic response results after removing global collapse cases (Fig. 3). Hence, the L/IM relationship for a single component does not consider collapse cases and thus for brevity is not explicitly given in some mathematical notations (i.e. $f_{E D P \mid I M}, \mu_{L_{i} \mid I M}$ and $\left.\sigma_{L_{i} \mid I M}^{2}\right)$

Figure 8 illustrates the L/IM relationships for two different components in the case study structure. The first (Fig. 8a) is an RC joint which was located in the second floor of the structure (e.g. EDP|IM 
relationship given in Figure $3 \mathrm{a}$ and $3 \mathrm{c}$ and L|EDP relationship in Figure 7), while the second (Fig. 8b) is a drywall partition located in the $8^{\text {th }}$ storey of the structure (e.g. EDP|IM relationship given in Figure $3 \mathrm{~b}$ and $3 \mathrm{~d}$ ). For both components, as would be expected, the loss due to direct damage increases as the ground motion shaking increases. For spectral acceleration levels in excess of $0.5 \mathrm{~g}$ the drywall partition is likely to be completely damaged, while the damage continues to increase in the RC joint (indicated by an increase in the mean repair cost) up to $S_{a}$ levels of $0.8 \mathrm{~g}$. As the seismic drift demand on the $8^{\text {th }}$ floor is significantly smaller than that on the lower half of the floors in the structure, a partition located on floors with higher seismic demand (for a given level of $S_{a}$ ) would sustain complete damage at significantly lower levels of spectral acceleration.

\subsection{L|IM for the entire structure}

The L|IM relationship for the entire structure given no-collapse can be obtained as the summation of the L/IM relationships for all of the components comprising the structure:

$$
\begin{aligned}
& \mu_{L_{T} \mid I M, N C}=\sum_{i=1}^{N c} \mu_{L_{i} \mid I M} \\
& \sigma_{L_{T} \mid I M, N C}^{2}=\sum_{i=1}^{N c} \sigma_{L_{i} \mid I M}^{2}+2 \sum_{i=1}^{N c} \sum_{j=1}^{i-1} \rho_{L_{i}, L_{j} \mid I M} \sigma_{L_{i} \mid I M} \sigma_{L_{j} \mid I M}
\end{aligned}
$$

where $N_{C}$ is the number of components in the structure; $\mu_{L_{T} \mid I M, N C}$ and $\sigma_{L_{T} \mid I M, N C}^{2}$ are the mean and variance in the total loss given IM and no collapse; and $\rho_{L_{i}, L_{j} \mid M M}$ is the correlation coefficient between the losses in various components. The correlation coefficient defines the linear dependency between the variances of different components within the structure and depends on the location within the structure (i.e. the correlation between different seismic demands within the structure) and the type of component (i.e. the correlation between damage fragility and repair actions of different components). Determination of the correlation matrix (comprised of the correlation coefficients) is a difficult task plagued by a lack of data, and is beyond the scope of this paper where it is simply assumed that all components are uncorrelated (a lower bound on the true uncertainty in the L/IM relationship).
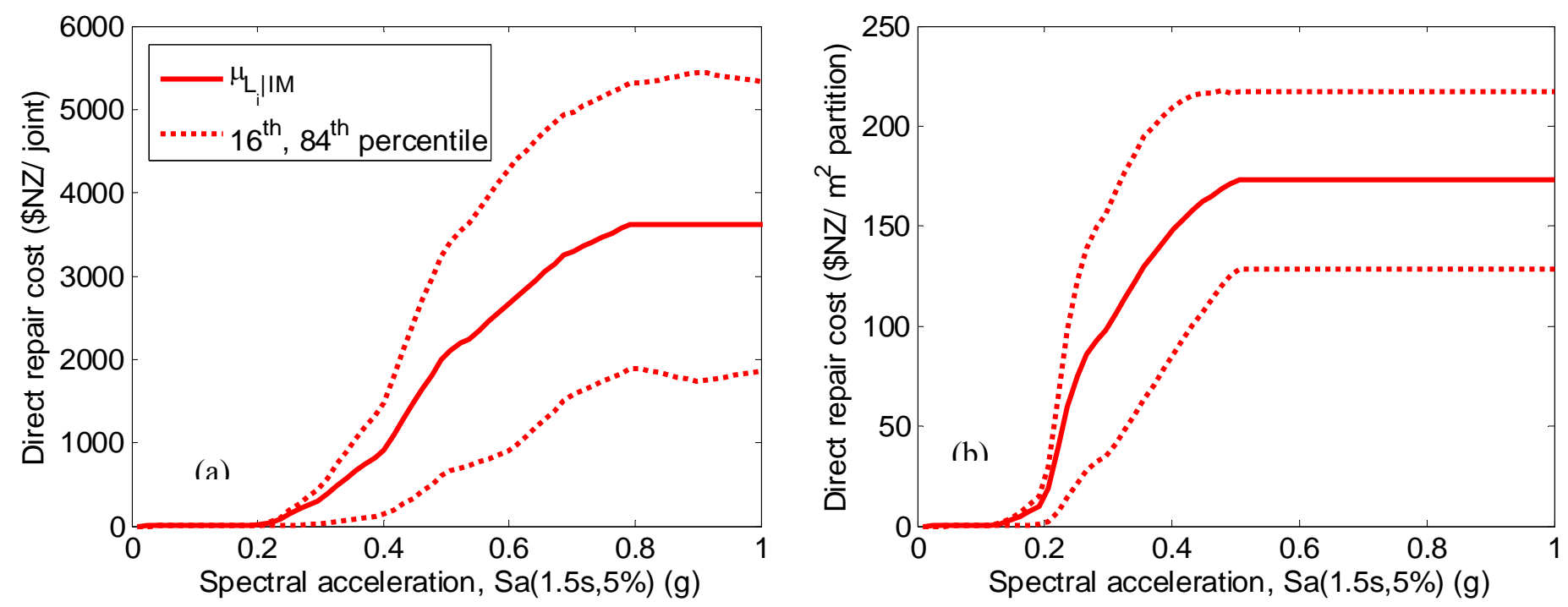

Figure 8: Loss given intensity relationships for (a) RC beam-column joint and (b) drywall partition.

The loss|IM relationship for the entire structure considering both collapse and non-collapse cases can be obtained from: 


$$
\begin{aligned}
\mu_{L_{T} \mid I M}= & \mu_{L_{T} \mid I M, N C}[1-P(C \mid I M)]+\mu_{L_{T} \mid C} P(C \mid I M) \\
\sigma_{L_{T} \mid I M}^{2}=\sigma_{L_{T} \mid I M, N C}^{2}[1-P(C \mid I M)] & +\sigma_{L_{T} \mid C}^{2} P(C \mid I M) \\
& +\left(\mu_{L_{T} \mid I M, N C}-\mu_{L_{T} \mid C}\right)^{2} P(C \mid I M)[1-P(C \mid I M)]
\end{aligned}
$$

where $\mu_{L_{T} \mid C}$ and $\sigma_{L_{T} \mid C}^{2}$ are the mean and variance of the loss given global collapse and $\mu_{L_{T} \mid I M}$ and $\sigma_{L_{T} \mid I M}^{2}$ are the mean and variance of the total loss once conditioning on collapse (and no collapse) has been removed. Figure 9 illustrates the loss|IM relationship for the entire structure for: (a) loss given IM and no collapse; (b) loss given collapse; and (c) loss given IM with no conditioning on collapse or no collapse. The expected loss and dispersion in the loss given collapse were computed based on the replacement cost of the structure plus an additional $8 \%$ to account for demolition and re-design (Aslani, 2005). The relatively small dispersion in the loss given no collapse case is due to the lowerbound assumption made here that losses between components are uncorrelated. Figure 9c illustrates the total loss given IM for the structure once both collapse and non-collapse cases are considered. As Equation 13 is simply the loss due to collapse and non-collapse weighted by the probability of each of the two mutually exclusive events occurring then it is clear that the L/IM relationship is similar to the $\mathrm{L} \mid \mathrm{IM}, \mathrm{NC}$ relationship for small levels of ground motion intensity (where $\mathrm{P}(\mathrm{C} \mid \mathrm{IM})$ is small), and is similar to the $\mathrm{L} \mid \mathrm{C}$ relationship for large levels of ground motion (where $\mathrm{P}(\mathrm{C} \mid \mathrm{IM})$ is large).
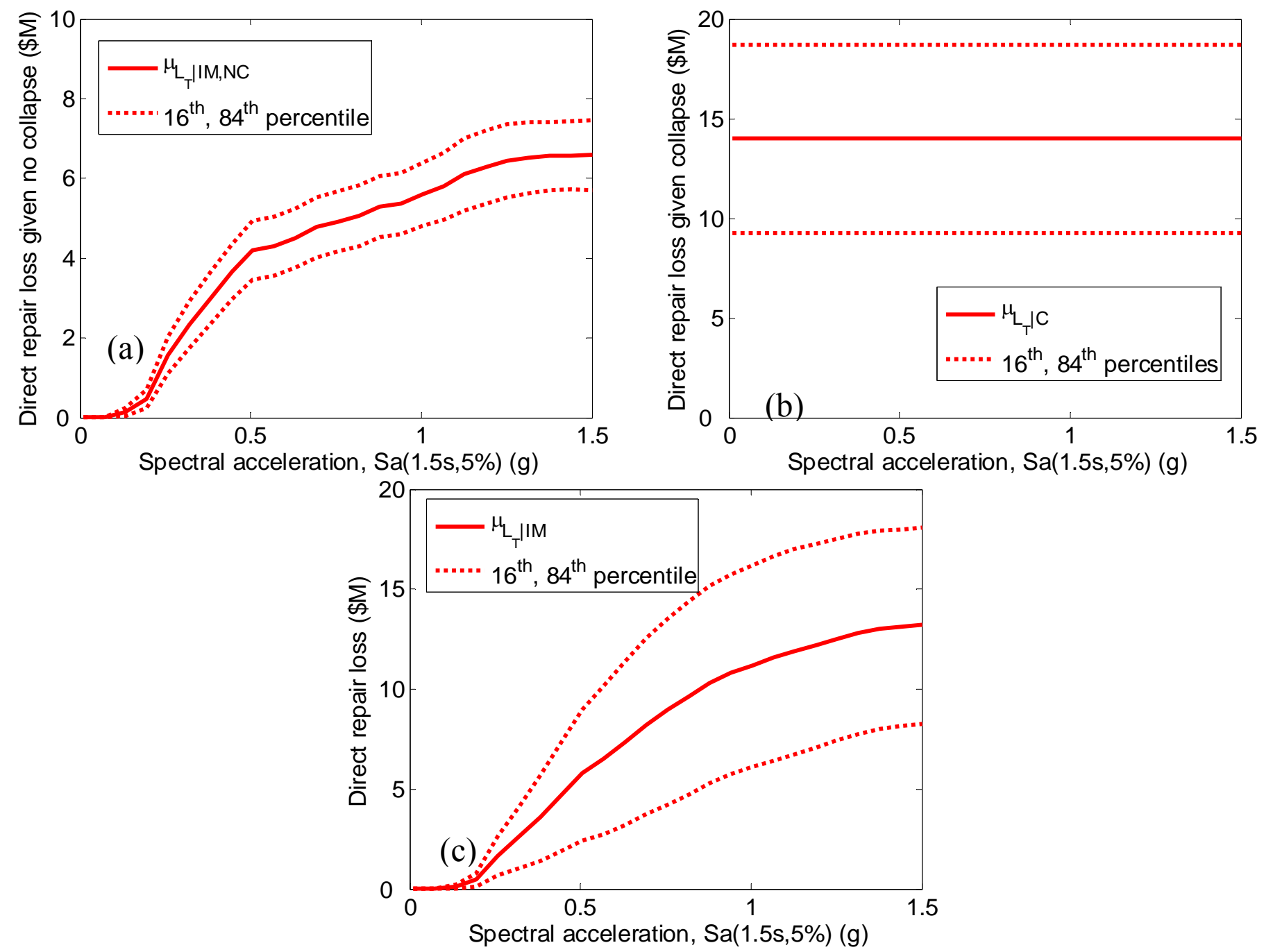

Figure 9: Loss given intensity for the entire structure given: (a) collapse does not occur; (b) collapse occurs; and (c) both collapse and non-collapse cases considered. 


\subsection{Deaggregation of L|IM by collapse}

Since the total loss given IM is an accumulation of damage to many different components on various floors of the structure it is insightful to deaggregate the loss to investigate key contributors (and therefore how the loss can be reduced most effectively) (Aslani, 2005). Figure 10a illustrates the deaggregation of the total loss by collapse and non-collapse cases for the analysed structure (Equation 13). As one would expect, for small levels of ground motion the probability of collapse is very small and therefore the majority of the loss is due to damage to individual components when the structure does not collapse. As the level of ground motion intensity increases the contribution of losses due to collapse increases. For example, if a ground motion observed during the 1995 Kobe earthquake occurred at the site of the structure it would be expected that $74 \%$ of the total loss in the structure would be due to the possibility of structural collapse. Figure 10b illustrates the effect on the L/IM collapse deaggregation for the same structure with a structural system assumed to be of a pre-1970's design (e.g. non-ductile, axial/shear critical RC frames). In this case it was assumed that the nonductile structure had a collapse fragility with mean $0.5 \mathrm{~g}$ and dispersion of 0.48 . This gives an annual rate of collapse of $1.0 \times 10^{-3}$ ( $4.9 \%$ probability of occurrence in 50 years), which is a representative collapse rate for such structures (Aslani, 2005). Comparing Figures 10a and 10b indicates that as the structure becomes more vulnerable to global collapse, the loss is further dominated by the collapse losses, and also the total loss for a given level of intensity also increases.
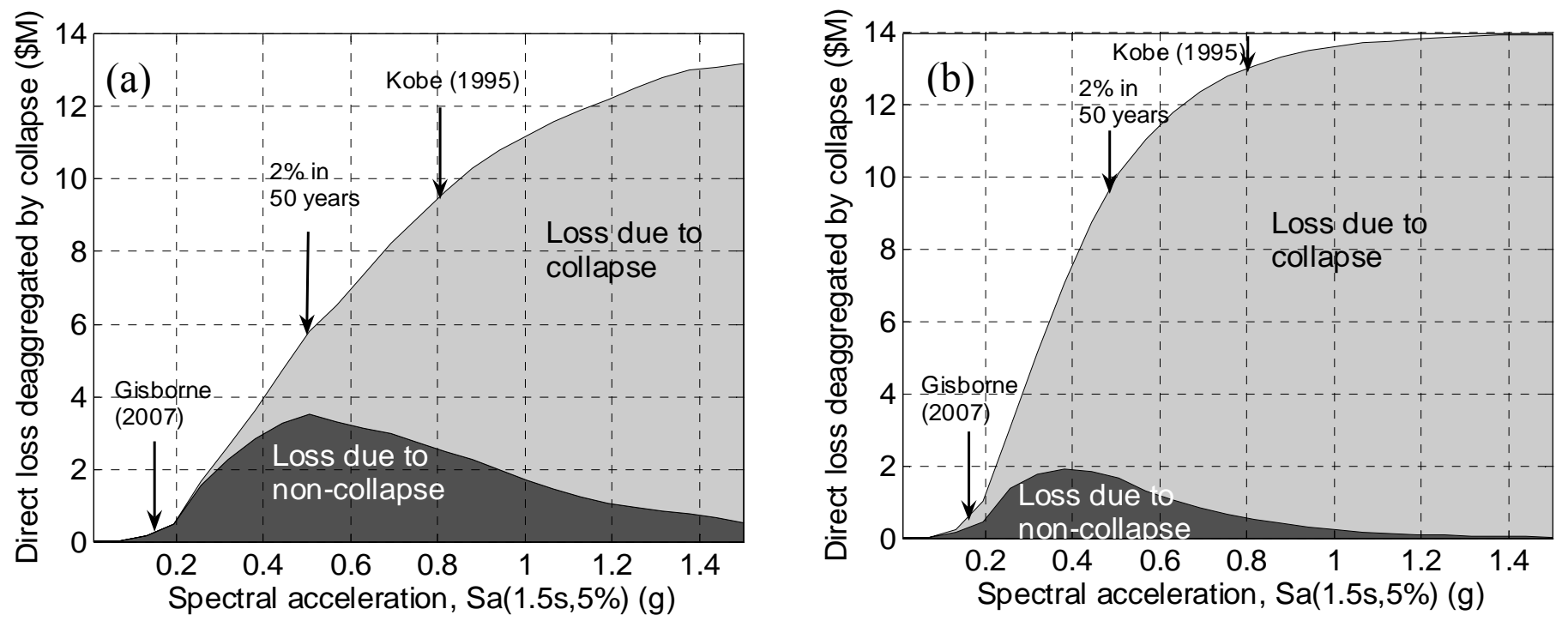

Figure 10: Deaggregation of the mean loss given intensity to collapse and non-collapse losses for (a) the case study structure and (b) for a similar structure with poor detailing.

\subsection{Deaggregation of L|IM by component type and location in building}

Figure 10 illustrates that for small levels of ground motion shaking a large portion of the total loss in structures is due to that which occurs in the absence of global collapse (this is particularly true for modern ductile designed structural systems as shown in the comparison of Figures 10a and 10b). Thus in the case of no-structural collapse, further insight can be obtained by deaggregation of the expected loss given no collapse (Equation 11). Figure 11 illustrates the deaggregation of the L/IM,NC relationship by different component types. It is immediately apparent that over all the observed ranges of ground motion considered here, loss due to damage in structural components (i.e. RC beam-column joints and Slab-beam-column connections) make up a very minor proportion of the total loss in the structure. Non-structural components such as drywall partitions and acoustical ceilings (as well as generic components) comprise a significant proportion of the total loss. Contents such as Server and Network equipment and Computers are also significant contributors toward the total loss in the structure. 


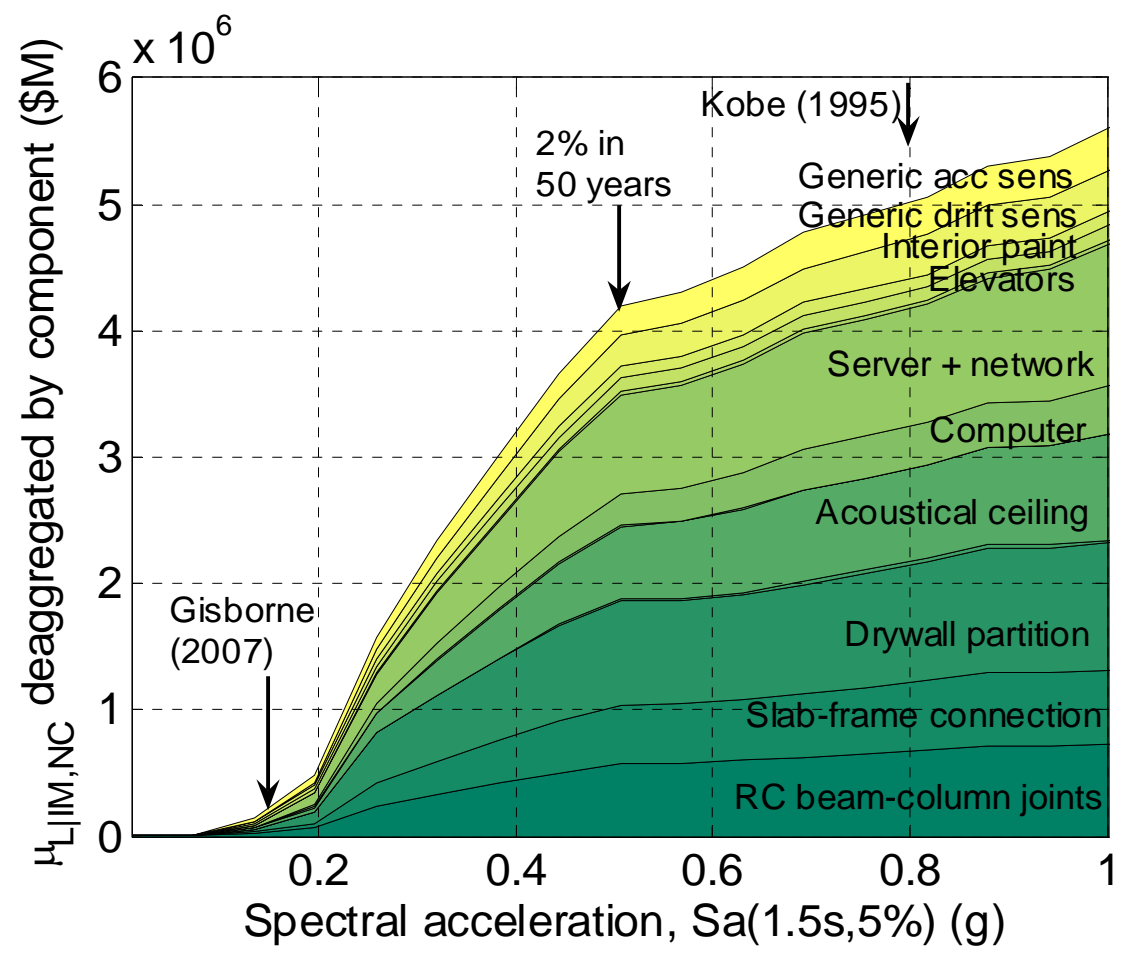

Figure 11: Deaggregation of the mean loss given no collapse relationship to contributions from different components.

As all of the different components within the structure have different fragilities and are subjected to different seismic demands (i.e. due to different locations in the structure) then further information can be obtained by looking at the loss deaggregation for a single level of ground motion shaking. Figure 12 illustrates the deaggregation of the loss given no collapse for a ground motion shaking of IM $=0.15 \mathrm{~g}$ $S_{a}$ which is approximately that observed in the recent Gisborne earthquake (Cousins and McVerry, 2008). For this level of ground motion shaking the expected direct loss was $\$ 0.23 \mathrm{M}$ for the case study structure. Figure 12a illustrates that for this relatively small level of shaking the total loss is dominated by that due to non-structural and contents damage and little loss is incurred due to structural damage (24\%). As noted by Mitrani-Reiser (2007) for this low level of ground shaking a large portion of the loss results from replacement and re-painting of damaged partitions and acoustical ceilings $(28 \%)$. Servers and computer equipment also have a significant contribution to the total loss $(20 \%)$, and generic acceleration sensitive components (16\%). Note that Figure 12a and 13a do not show components which contribute less than $1 \%$ to the total loss (e.g. exterior glazing, automatic sprinklers). Figure 12b illustrates the contribution of the total loss as a function of the different storey numbers. Recall that most of the components were assumed to have the same quantity for each floor in the structure, with the exception of the server and network equipment, roof mounted equipment and elevators. The server and network equipment is the primary reason for the relatively large levels of loss on the $3^{\text {rd }}, 6^{\text {th }}$ and $10^{\text {th }}$ floors, while the elevator damage also makes a significant contribution to the loss on the ground floor. 
(a)

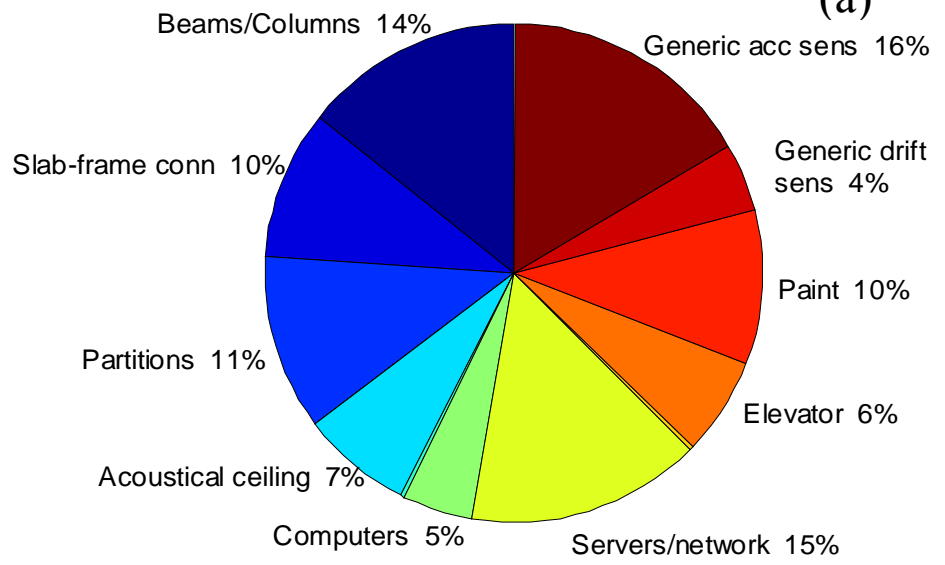

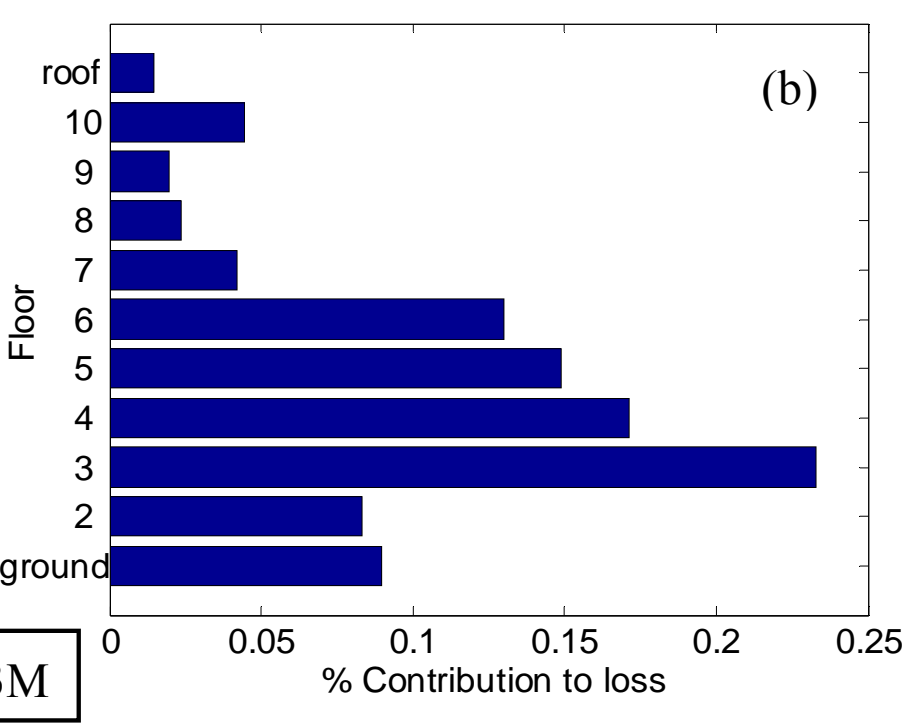

Figure 12: Deaggregation of the expected loss given no collapse for IM=0.15g $S_{a}$ (Gisborne, 2007) by: (a) component type and (b) by floor.

Figure 13 illustrates the L|IM,NC deaggregation for IM $=0.5 \mathrm{~g} S_{a}$ which is the level of ground motion shaking with a $2 \%$ probability of exceedance in 50 years (return period approximately 2475 years) at the site. For this level of shaking the expected loss was estimated to be $\$ 4.2 \mathrm{M}$. Trends observed in Figure 12a in regard to the loss being dominated by non-structural and contents damage are also evident at this higher level of ground shaking. Notable changes from Figure 12 however are the reduction in the proportion of damage due to re-painting of interior walls; damage to elevators, and an increase in the proportion of loss due to damage of the partitions and acoustical ceilings. The deaggregation of damage over the height of the structure is also significantly different from that at the lower level of ground motion shaking. The effect of the server and network equipment in the distribution of loss over the height of the structure is very evident, while the reduction in proportion of damage due to the elevator reduces the contribution of loss in the ground floor. Despite the significant increase in drift demands (Fig. 4a) on the lower floors of the structure for this level of shaking relative to the results in the previous figure $\left(S_{a}=0.15 \mathrm{~g}\right)$, a significant portion of the loss still originates from the upper floors. This is due to an increase in the acceleration demands on the upper floors which are of a large enough magnitude to damage a large proportion of fragile acceleration-sensitive components. Figure 3 illustrated that as the ground motion shaking increases, both acceleration and drift demands become largest in the lower floors of the structure (illustrated by the domination of losses in these floors in Figures 12a and 13a). This localisation of demand in the lower stories prevents components in the upper stories sustaining total damage, and thus the reason why the total loss given no collapse (Fig. 9a) even at large IM levels, is still well below the total loss given collapse occurs. 


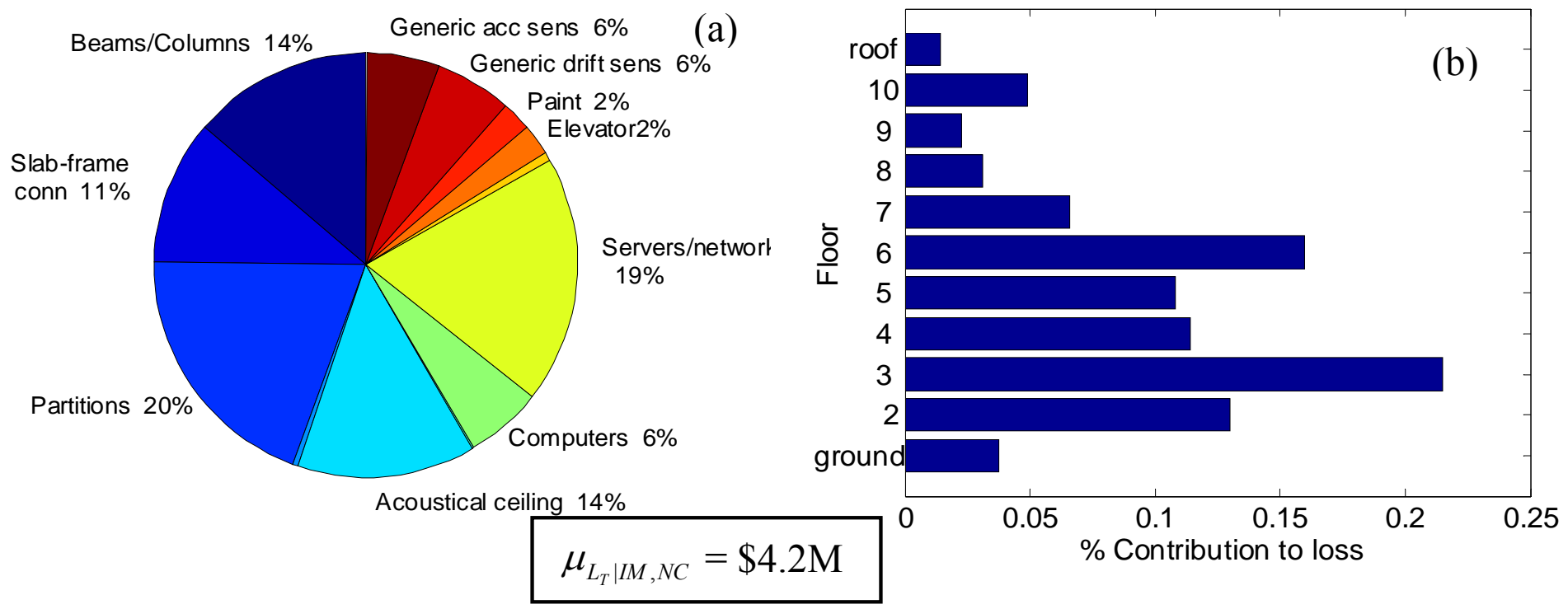

Figure 13: Deaggregation of the expected loss given no collapse for IM=0.50g $S_{a}(2 \%$ in 50 year probability of exceedance) by: (a) component type and (b) by floor.

\section{EXPECTED ANNUAL LOSS}

The above L|IM relationships are useful in determining the variation in loss as the ground motion increases. However, the ground motion hazard is needed in conjunction with the L/IM results in order to appreciate the frequency of exceedance for each of the ground motion IM levels. The L/IM relationship can be combined directly with the ground motion hazard to get the moments of annual loss that occurs on a per annum basis by:

$$
\begin{aligned}
\mu_{L_{T}} & =\int \mu_{L_{T} \mid I M}\left|\frac{d \lambda_{I M}}{d I M}\right| d I M \\
\sigma_{L_{T}}^{2} & =\int\left[\sigma_{L_{T} \mid I M}^{2}+\mu_{L_{T} \mid I M}^{2}\left|\frac{d \lambda_{I M}}{d I M}\right| d I M-\mu_{L_{T}}^{2}\right.
\end{aligned}
$$

where $\mu_{L_{T}}$ and $\sigma_{L_{T}}^{2}$ are the mean and variance of the annual loss.

Expected Annual Loss $\left(\mathrm{EAL}=\mu_{L_{T}}\right)$ is a seismic performance measure which is particularly useful for decision makers as it contains information on the seismic performance of a structure over a range of different levels of ground motion intensity within a single number. EAL has been used extensively by Porter and co-workers (e.g. Porter and Kiremidjian, 2001; Mitrani-Reiser, 2007) as well as others in risk management decision making. For the case study structure in was found that the EAL was $\$ 11,700$ which relates to approximately $0.08 \%$ of the replacement cost of the structure. Figure $14 \mathrm{a}$ illustrates the net present value (NPV) of the expected loss over time for the structure based on a discount rate of $6 \%$. The discount rate is used to account for the time value of money and represents the difference between interest and inflation rates. Figure 14b illustrates the deaggregation of the EAL as a function of ground motion intensity. It indicates that the majority of the EAL is attributed to the occurrence of ground motions between $0.25-0.75 \mathrm{~g} S_{a}$ (with smaller ground motions not causing significant damage, and larger ground motions occurring very infrequently). Although not presented here there are several other possible ways to deaggregate the EAL such as by components, collapse, and location in the structure (as for the L|IM deaggregations shown in Figures 10-13). 

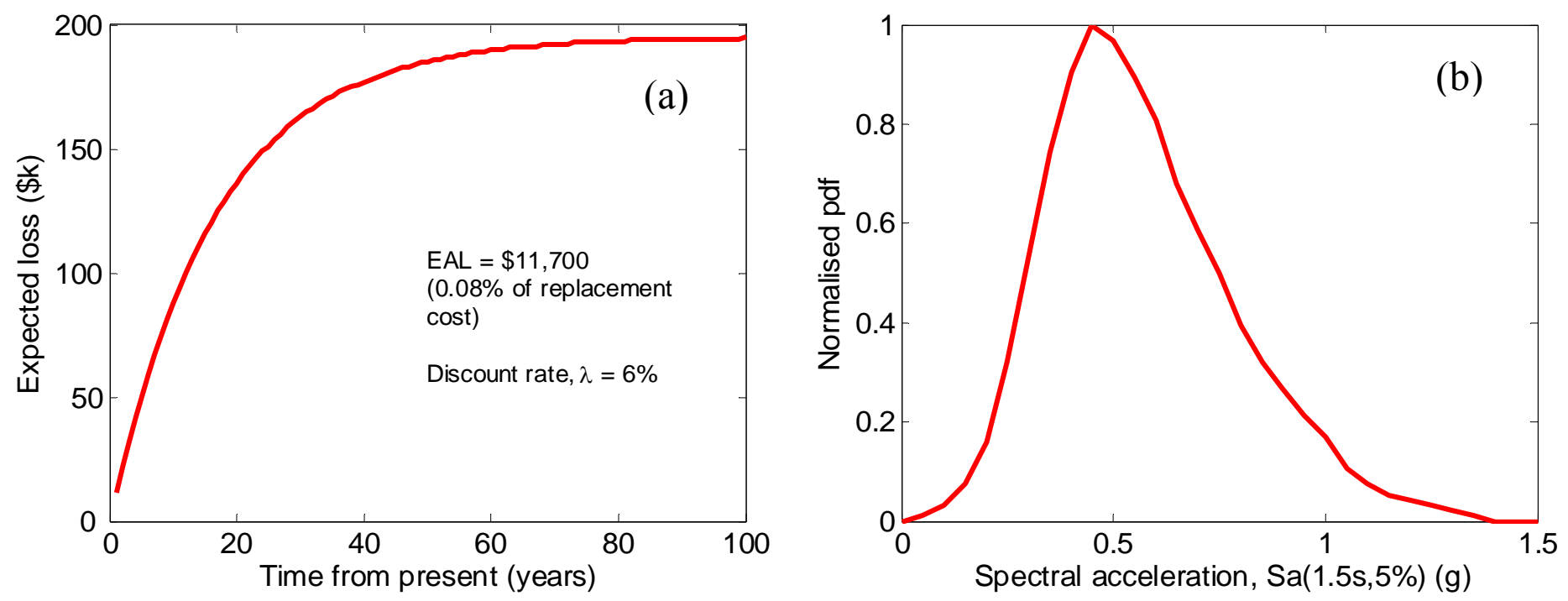

Figure 14: Expected loss results for case study structure: (a) over time considering net discount rate; and (b) deaggregation of EAL by intensity measure.

As an indication of the seismic performance of non code-complying structures, the case study structure with modified collapse capacity which was discussed in Figure 10b was found to have an EAL of $\$ 20,500$, with a large proportional of the EAL due to collapse events. Despite the significantly poor seismic performance such a structural system, the EAL is still only $75 \%$ larger than that of the case study structure considered here. This is due to the aforementioned observation that economic loss in structures during small to moderate ground motions is dominated by damage to nonstructural components and contents rather than structural components.

\subsection{Application of EAL for retrofit decision making}

Figure 15 illustrates an example of how EAL can be used as a method for determining the viability of different design alternatives or retrofit solutions. In this case the current structure is the case study structure with an EAL of $\$ 11,700$. A retrofit solution based on the installation of viscous dampers is used to primarily reduce acceleration demands in the structure due to ground motion shaking and has an assumed cost of $\$ 40,000$. The retrofit will reduce the EAL to $\$ 8,000$. As the NPV of expected loss over time accounting for the discount rate is computed by:

$$
E_{L}=\frac{\left(1-e^{-\lambda t}\right)}{\lambda} E A L+C_{R}
$$

where $\lambda$ is the discount rate; $t$ is the time in years; and $C_{R}$ is the retrofit cost. Then by equating Equation 17 for the as-is structure $\left(C_{R}=0\right)$ and retrofitted structure the time after which the retrofit is economically feasible can be found by:

$t_{c r}=\frac{-1}{\lambda} \ln \left(1-\frac{\lambda}{(1-\alpha)} \frac{C_{R}}{E A L}\right)$

where $\alpha$ is a parameter indicating the reduction in the EAL due to the retrofit (i.e. $\alpha=8,000 / 11,700=0.68)$. Using Equation 18 it is found that this critical time for retrofit viability is 17 years (Fig. 15). Thus the service life of the structure should be greater than 17 years in order for the retrofit to be beneficial. The example above is based on decision-making for a client who is risk neutral. When risk attitude is taken into account (decision makers are typically risk averse toward low probability high consequence events such as earthquakes) then measures such as the Certainty Equivalent (CE) should be used (Porter and Kiremidjian, 2001).

In the example presented above EAL was used as the performance measure of interest. In certain 
cases the specific performance measure used will depend on the perspective from which the decision making is made. For example, performance measures for an owner and an occupant will be different, with the owner principally interested in minimising damage and business downtime, while the client is interested in minimising human loss and contents damage.

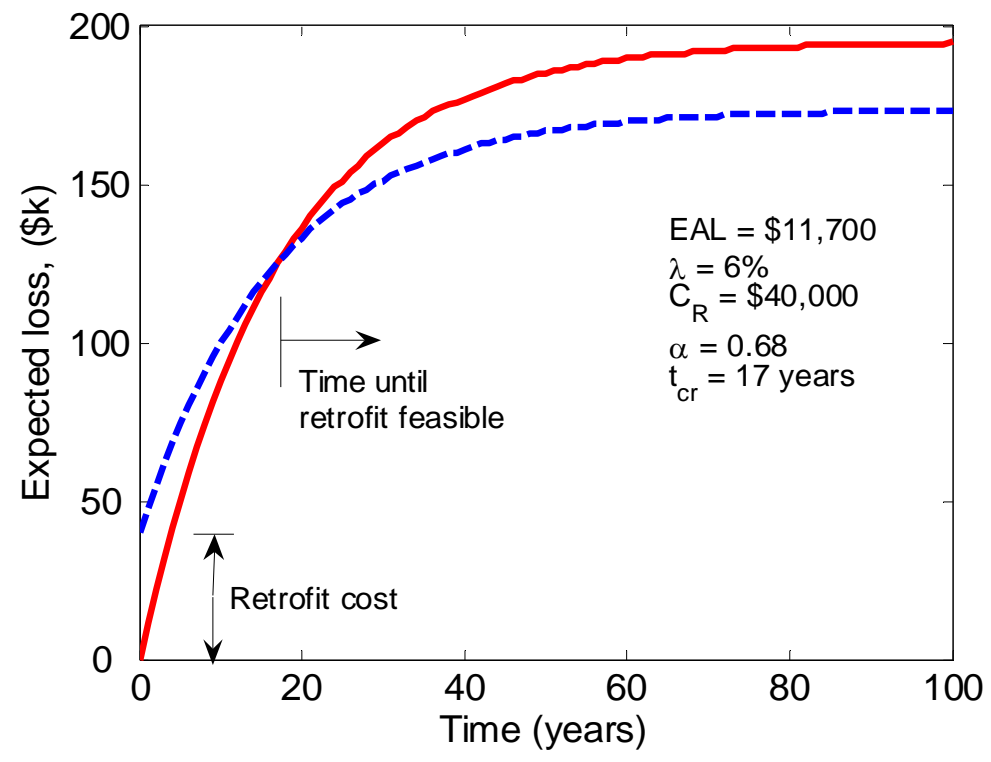

Figure 15: Use of EAL in determine effective retrofitting solutions

\section{LOSS HAZARD}

In a similar manner to the computation of the EDP hazard curves presented earlier, the L/IM relationship can be combined with the ground motion hazard curve to obtain a loss hazard curve for the structure:

$$
\lambda_{L_{T}}=\int G\left(L_{T} \mid I M\right)\left|\frac{d \lambda_{I M}}{d I M}\right| d I M
$$

Where $G\left(L_{T} \mid I M\right)$ is the CCDF of the L/IM relationship which can be obtained by:

$$
G\left(L_{T} \mid I M\right)=G\left(L_{T} \mid I M, N C\right)[1-P(C \mid I M)]+G\left(L_{T} \mid C\right) P(C \mid I M)
$$

where $G\left(L_{T} \mid I M, N C\right)$ and $G\left(L_{T} \mid C\right)$ are the CCDF's of the $\mathrm{L} \mid \mathrm{IM}, \mathrm{NC}$ and $\mathrm{L} \mid \mathrm{C}$ relationships, respectively. The $\mathrm{L} \mid \mathrm{IM}, \mathrm{NC}$ distribution is assumed to have a normal distribution based on the central limit theorem, while the $\mathrm{L} \mid \mathrm{C}$ distribution is assumed to be lognormal based on past research (Aslani, 2005). Figure 16 illustrates the loss hazard curve for the case study structure. The loss hazard curve gives the annual frequency of exceeding various levels of economic loss in the structure. For reference, the $10 \%$ and $2 \%$ probability of exceedance in 50 year curves are shown which have loss values of approximately $\$ 1.5 \mathrm{M}$ and $\$ 4.5 \mathrm{M}$, respectively. The loss-hazard curve is another figure (in addition to the expected loss) which can be useful in loss-based decision making, particularly for riskaverse decision makers who are concerned with the frequency of various economic losses as opposed to just the expected annual loss. 


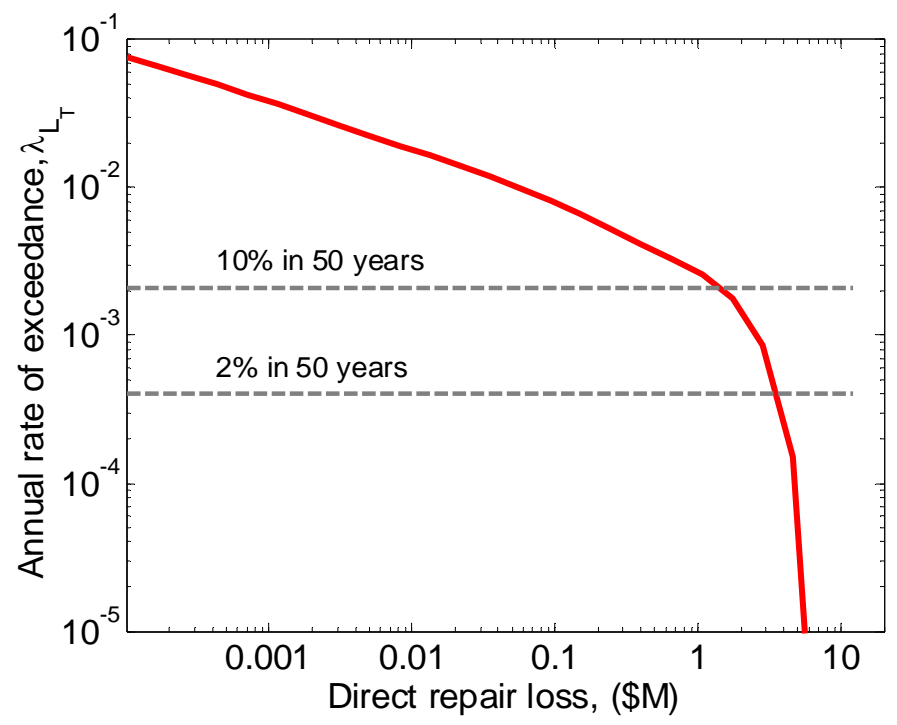

Figure 16: Loss hazard curve for the case study structure.

\section{LIMITATIONS OF LOSS ASSESSMENT}

Throughout this manuscript various assumptions have been made regarding the loss assessment in order to focus its use in the decision making process without attending significantly to many technical details. Some of the simplifying assumptions made could cause significant error in the outputs of the loss-assessment (and the resulting decisions made) and therefore should be appropriately considered. An outline of considerations not made in the presented example is given below, along with recent research in each of these areas where appropriate.

Economic losses due to human causality and injury and business disruption/downtime were not included in the example presented in this manuscript, but both have been shown to be significant in previous earthquakes (in many cases more than loss due to direct damage). Models for considering both of these losses are still in their infancy and an early attempt within this loss-assessment methodology can be found in Mitrani-Reiser, (2007).

The direct repair cost estimates used in this example did not consider the effects of demand surge. Demand surge refers to the observed increase in the unit cost of labour and materials when demand for resources far exceeds the resource supply. Preliminary work on quantifying demand surge effects can be found in Boissonnade (2007).

The seismic hazard used for the site considers only the likely occurrence of ground motions due to mainshocks. It is typical following a mainshock ground motion that multiple aftershock ground motions will also occur. Yeo and Cornell (2005) provide recent work illustrating how aftershock considerations can be modelled within loss estimation procedures.

Stiff soil at the site of the structure was assumed and therefore it was a valid assumption that the effects of ground motion modification due to soil non-linearities and damage to the foundation was not significant. Many structures (particularly lifelines such as bridges) are founded on pile foundations which are located on loose sands susceptible to liquefaction and lateral spreading. In such cases, ground motion modification and foundation damage may contribute significantly toward the total loss in the structure during strong ground motion shaking.

\section{DISCUSSION: IMPROVING STRUCTURAL PERFORMANCE}

Figures 12a and 13a illustrate that for a code-conforming structural system, economic loss due to both moderate and large ground motion shaking is mostly caused by damage to non-structural components 
and contents and not due to structural damage or global collapse. This indicates that the improvement of seismic performance of structural systems requires a focus on improving the performance of the entire structure and not just the structural system specifically. As an example, based on the results presented in this manuscript, emerging jointed precast concrete systems (Priestley, et al, 1999; Mander and Cheng 1997) which are designed to undergo the same levels of seismic demand as that of conventionally designed ductile structures with minimal structural damage will only mildly improve the performance of the entire system (an ambitious estimate could be made by assuming that all structural damage was avoided thus reducing the losses by approximately $25 \%$ ). It should be noted however, that downtime (business disruption) losses have not been considered here and in some cases downtime due to structural damage may be excessive. Therefore significantly improved seismic performance of buildings can be obtained either by: (i) improving component fragilities via modifying connection details on non-structural components connected to the structural frame; fastening acceleration sensitive components which topple, base isolating expensive components (e.g. servers, electrical equipment); or (ii) by reducing seismic demands throughout the structure for the same level of ground shaking via increased viscous and hysteretic damping using dissipation devices or base isolation devices.

\section{DISCUSSION: SLAT OVERVIEW}

All of the loss-based computations performed in this manuscript have used the specially developed software SLAT (Seismic Loss Assessment Tool) (Bradley, 2008). SLAT has been developed as a general-purpose loss assessment tool which is capable of performing various loss assessment procedures with various types of input data (in regard to complexity). Although SLAT is still only currently in an 'alpha' version it is intended to make the tool available in the public domain in order to allow the seismic design of structures to be based on more rational measures of seismic performance.

\section{CONCLUSIONS}

A seismic loss estimation methodology has been presented and applied for the seismic assessment of a 10 storey reinforced concrete moment frame structure. The seismic loss estimation methodology enables quantification of the seismic risk of engineered structures thus allowing consistent communication and rational decision making regarding the acceptance or mitigation of the seismic risk. It was illustrated how the seismic loss estimation methodology can be used to interpret seismic performance in terms of seismic demand and associated economic loss as a function of the ground motion intensity. Economic loss due to non-structural components and contents was shown to be significant over a large range of ground motion shaking intensities. The wealth of information regarding system performance that is possible using deaggregation within seismic loss estimation methods can be used to target areas of seismic vulnerability and therefore efficiently improve seismic performance. In particular, deaggregation illustrated that economic loss due to non-structural components and contents was significant over a large range of ground motion shaking intensities, as well as how the distribution of losses over the height of the structure can be related to seismic response of the structure. A retrofit example was used to illustrate how expected annual loss (EAL) can be used within a decision making framework to make rational loss-based decisions.

\section{ACKNOWLEDGEMENTS}

Financial support of the first author from the New Zealand Tertiary Education Commission Bright Futures scheme is appreciated. The authors also thank Mr John Buchan of the Christchurch City Council for providing building inventory information.

\section{REFERENCES:}

Ang A.H.S., Tang W.H. 1975. Probability Concepts in Engineering Planning and Design: Volume I - Basic Principles. John Wiley \& Sons, Inc. 
Aslani H. 2005. Probabilistic Earthquake Loss Estimation and Loss Disaggregation in Buildings. Ph.D. Thesis, John A. Blume Earthquake Engineering Centre, Dept. of Civil and Environmental Engineering, Stanford University, Stanford, CA. 382 pages.

Aslani H., Miranda E. 2005. Probability-based Seismic Response Analysis. Engineering Structures; 27 (8). 1151-1163.

Boissonnade A. 2007. Modelling demand surge. Workshop on Risk Acceptance and Risk Communication. Stanford University. http://www.ripid.ethz.ch/

Bradley B.A. 2008. SLAT: Seismic Loss Assessment Tool, version 1.12 user manual. Computer Program Library, Department of Civil Engineering, University of Canterbury, Christchurch, New Zealand

Buchan J. 2007. Internal report of non-structural and contents inventories for the Christchurch Council Chambers building, Christchurch, New Zealand.

Bull D. and Brunsdon, D. 1998. Examples of Concrete Structural Design to New Zealand Standards 3101, Cement and Concrete Association, New Zealand

Carr A.J. 2004. RUAUMOKO: Inelastic Dynamic Computer Program. Computer Program Library, Department of Civil Engineering, University of Canterbury, Christchurch, New Zealand.

Chopra A.K., and Goel R. 2004. A modal pushover analysis procedure to estimate seismic demands for unsymmetric-plan buildings. Earthquake. Engineering and Structural. Dynamics. 33. 903-927.

Cousins J. and McVerry G. 2007 Ground motion spectra for the 2007 Gisborne earthquake. Internal preliminary report. GNS science.

Elwood K.J., and Moehle J.P. 2008. Dynamic Collapse Analysis for a Reinforced Concrete Frame Sustaining Shear and Axial Failures. Earthquake Engineering and Structural Dynamics (In Press).

Fajfar P. 2002. Structura $\downarrow_{h}$ analysis in earthquake engineering - A breakthrough of simplified nonlinear methods. Proceedings of the 12 European Conf. on Earthquake Engng, London, UK.

Ibarra L.F., Krawinkler H. 2005. Global collapse of frame structures under seismic excitations. Report No. PEER 2005/06, Pacific Earthquake Engineering Research Center, University of California at Berkeley, Berkeley, CA.

Insurance Information Institute, 2006. Earthquakes: Facts and Statistics. http://www.iii.org/media/facts/statsbyissue/earthquakes/

Jalayer F. 2003. Direct Probabilistic Seismic Analysis: Implementing Non-linear Dynamic Assessments. PhD Thesis, Department of Civil and Environmental Engineering, Stanford University. 272pages.

Mander J.B., Cheng C.T. 1997. Seismic Resistance of Bridge Piers Based on Damage Avoidance Design, Technical Report NCEER-97-0014. National Center for Earthquake Engineering Research: Buffalo, NY.

Mander J.B., Dhakal R.P., Mashiko N., Solberg K.M. 2006. Incremental dynamic analysis applied to seismic financial risk assessment of bridges. Engineering Structures. 29 (10). 2662-2672.

Medina R.A, and Krawinkler H. 2003. Seismic demands for nondeteriorating frame structures and their dependence on ground motions. Report No. 144, John A. Blume Earthquake Engineering Center, Department of Civil and Environmental Engineering, Stanford University, Stanford, CA.. http://blume.stanford.edu/Blume/TRList.htm

Mitrani-Reiser J. 2007. An Ounce of Prevention: Probabilistic Loss Estimation for Performance-based Earthquake Engineering. PhD Thesis. California Institute of technology, CA 173pp.

Moghadam A.S., and T\$o W.K. 2000. Pushover analysis for asymmetric and set-back multi-story buildings. Proceedings of the 12 World Conf. on Earthquake Engineering, Auckland, New Zealand. Paper No. 1093.

NZS3101-95. 1995. Concrete Structures Standard: NZS3101. Standards New Zealand. Wellington, New Zealand.

NZS1170. 2004. NZS 1170.5:2004. Standards New Zealand, Wellington, New Zealand.

Penelis G.G, and Kappos A.J. 2002. 3D pushover analysis: The issue of torsion. Proceedings of the $12^{\text {th }}$ European Conf. on Earthquake Engineering, London, UK.

Porter K.A., and Kiremidjian A.S. 2001. Assembly-based Vulnerability of Buidlings and its uses in Seismic Performance Evaluation and Risk Management Decision-making. Report 139-. John A Blume Earthquake Engineering Centre. Stanford University.

Porter K., Kennedy R., Bachman R. 2007. Creating Fragility Functions for Performance-based Earthquake 
Engineering. Earthquake Spectra; 23 (2). 471-489.

Priestley M.J.N., Sritharan S., Conley J.R., Pampanin S. 1999. Preliminary Results and Conclusions from the PRESSS Five-Story Precast Concrete Test Building, PCI Journal; 44 (6). 42-67.

Shome N., Cornell C.A. 2000. Structural Seismic Demand Analysis: Consideration of "Collapse". $8^{\text {th }}$ ASCE Specialty Conference on Probabilistic Mechanics and Structural Reliability. University of Notre Dame, South Bend, Indiana.

Shome, N., and Cornell, C.A., 1999. Probabilistic seismic demand analysis of nonlinear structures. Report No. RMS-35, RMS Program, Stanford University, Stanford, CA.

Stirling M.W., McVerry G.H., Berryman K.R. 2002. A New Seismic Hazard Model for New Zealand, Bulletin of the Seismological Society of America. 92 (5). 1878-1903.

Taghavi S., and Miranda E. 2005. Response assessment of non-structural building elements. Peer Report No 2003/05. http://peer.berkeley.edu/publications/peer_reports.html

Vamvatsikos D., Cornell C.A. 2002. Incremental Dynamic Analysis. Earthquake Engineering and Structural Dynamics. 31. 491-514.

Yeo G.L., and Cornell C.A. 2005. Stochastic Characterisation and Decision Bases under Time-Dependent Aftershock Risk in Performance-based Earthquake Engineering. Report 149. John A. Blume Earthquake Engineering Centre. Stanford University.

Zareian F., Krawinkler H., 2007. Assessment of probability and design for collapse safety. Earthquake Engineering and Structural Dynamics, 36 (13).1901-1914. 